\title{
Reevaluating the Fusobacterium Virulence Factor Landscape
}

Ariana Umana ${ }^{1 *}$, Blake E. Sanders ${ }^{1 *}$, Chris C. Yoo ${ }^{1}$, Michael A. Casasanta ${ }^{1}$, Barath Udayasuryan $^{2}$, Scott $^{2}$ S. Verbridge ${ }^{2}$, Daniel J. Slade ${ }^{1, \#}$

${ }^{1}$ Department of Biochemistry, Virginia Polytechnic Institute and State University, Blacksburg, VA, USA.

${ }^{2}$ Laboratory of Integrative Tumor Ecology, and Virginia Tech - Wake Forest School of Biomedical Engineering and Sciences,

Blacksburg, VA, USA

${ }^{*}$ These authors contributed equally

\# To whom correspondence should be addressed: Dr. Daniel J. Slade, Department of Biochemistry, Virginia Polytechnic Institute and State University, Blacksburg, VA 24061. Telephone: +1 (540) 231-2842. Email: dslade@vt.edu

ABSTRACT Fusobacterium are Gram-negative, anaerobic, opportunistic pathogens involved in multiple diseases, including the oral pathogen Fusobacterium nucleatum being linked to the progression and severity of colorectal cancer. The global identification of virulence factors in Fusobacterium has been greatly hindered by a lack of properly assembled and annotated genomes. Using newly completed genomes from nine strains and seven species of Fusobacterium, we report the identification and correction of virulence factors from the Type 5 secreted autotransporter and FadA protein families, with a focus on the genetically tractable strain $F$. nucleatum subsp. nucleatum ATCC 23726 and the classic typed strain $F$. nucleatum subsp. nucleatum ATCC 25586. Within the autotransporters, we employed protein sequence similarity networks to identify subsets of virulence factors, and show a clear differentiation between the prediction of outer membrane adhesins, serine proteases, and proteins with unknown function. These data have defined protein subsets within the Type 5a effectors that are present in predicted invasive strains but are broadly lacking in passively invading strains; a key phenotype associated with Fusobacterium virulence. However, our data shows that prior bioinformatic analysis that predicted species of Fusobacterium to be non-invasive can indeed invade human cells, and that pure phylogenetic analysis to determine the virulence within this bacterial genus should be used cautiously and subsequently paired with experiments to validate these hypotheses. In addition, we provide data that show a complex interplay between autotransporters, MORN2 domain containing proteins, and FadA adhesins that we hypothesize synergistically contribute to host cell interactions and invasion. In summary, we report that accurate open reading frame annotations using complete Fusobacterium genomes, in combination with experimental validation of invasion, redefines the repertoire of virulence factors that could be contributing to the species specific pathology of multiple Fusobacterium induced infections and diseases.

IMPORTANCE Fusobacterium are emerging pathogens that contribute to the progression and severity of multiple mammalian and human infectious diseases, including colorectal cancer. Despite a validated connection with disease, a limited number of proteins have been characterized that define a direct molecular mechanism for pathogenesis in a diverse range of host tissue infections. We report a comprehensive examination of virulence associated protein families in multiple Fusobacterium species, and show that complete genomes facilitate the correction and identification of multiple, large Type 5a secreted autotransporter genes in previously misannotated or fragmented genomes. In addition, we use protein sequence similarity networks and human cell invasion experiments to show that previously predicted non-invasive strains can indeed enter human cells, and that this is likely due to the expansion of specific virulence proteins that drive F. nucleatum infections and disease.

KEYWORDS Fusobacterium nucleatum, Fusobacterium necrophorum, virulence factor, autotransporter, Type 5 secretion, FadA, T5SS, Fap2, colorectal cancer, adhesin, host-pathogen, Lemierre's Syndrome 


\section{INTRODUCTION}

Bacterial pathogens use a repertoire of diverse virulence proteins to establish infection and confer long-term survival in their respective hosts and environments. A central theme to these virulent phenotypes is the expression of surface exposed and secreted proteins that interact with a variety of macromolecule receptors on host cells (1-4). In addition, these proteins can be deployed by intracellular bacteria within the host cytoplasm or niche-specific vacuole to confer survival, replication, and dissemination. These phenotypes in Gram-negative bacteria are frequently achieved by using large, multi-protein secretion systems, or nanomachines, divided into six categories (Type 1-6; T1-6SS)(5). While these are the most common systems to introduce virulence factors into the host or competing bacteria, Fusobacterium are unique in that they lack all of the aforementioned multi-protein secretion systems except for the Type 5 secretion system (T5SS)(6). This system is unique in that it is not a large nanomachine, but is divided into five distinct categories (T5a-eSS) that are composed of only one (T5a,c,d,e) or two proteins (T5bSS)(3). These subtypes can be divided into monomeric autotransporters $(5 a, d)(7,8)$, two-partner secretion systems $(5 b)(9)$, homo-trimeric autotransporters $(5 c)(10)$, and intimins $(5 e)(11,12)$. The majority of characterized autotransporters are large adhesins or proteases of the T5aSS, or homo-trimeric adhesins of the T5cSS that include YadA from Yersinia pestis (13). A large scale bioinformatic analysis showed that $100 \%$ of Fusobacteria genomes contain T5aSS proteins; the highest percentage in all Gram-negative bacteria tested (14).

Fusobacterium are Gram-negative, non-motile, anaerobic bacteria generally isolated from the human oral cavity (Fig. 1A), but can also infect other higher mammals including cattle and sheep (15-17). A strong correlation has been established between the presence of $F$. nucleatum in colorectal cancer tumors and a direct induction of increased tumor size, frequency, and stimulation of a pro-inflammatory tumor microenvironment (Fig. 1B) (18-20). The interaction of this bacterium with host cells also induces chemoresistance by blocking apoptosis (21), and viable bacteria have been shown to travel within metastatic cells to the liver (22). In addition, increased $F$. nucleatum load within patient sampled tumors correlates with decreased human life expectancy (23).

In a recent study, Fusobacterium species were bioinformatically divided into actively invading species (F. nucleatum, F. periodonticum, F. varium, F. ulcerans) (Fig. 1C), passively invading species that are believed to need a compromised epithelial barrier for cellular entry ( $F$. necrophorum, $F$. gonidiaformans), and those with unknown invasive potential (F. mortiferum)(24). Despite the extensive phylogenetic analysis of Fusobacterium and our increasing understanding of what is required to be a virulent strain, our knowledge of the specific virulence mechanisms remains limited. For instance, it was previously shown that multiple $F$. necrophorum and $F$. mortiferum strains were significantly more invasive than $F$. nucleatum strains into keratinocytes, which is in direct conflict with bioinformatic reports that place these species in the non-invasive or passively invasive category $(24,25)$. F. necrophorum and $F$. mortiferum are invasive but have not been associated with colorectal cancer, which raises an additional question of how virulence is truly regulated in this disease. Further studies are needed to differentiate the importance of invasion versus only binding to host cell surfaces. For instance, a recent study reported that $F$. nucleatum is able to induce chemoresistance by interacting with surface-exposed toll-like receptors: (21) However, we note that the strain used in this study was highly invasive, yet the amount of intracellular bacteria was not determined. As previously characterized mutants with decreased invasion into human cell lines are also deficient in cellular binding, it could be that there is a complex phenotype that bridges the need for initial host cell docking, and subsequent intracellular modulation of cell signaling.

There is a clear gap in our understanding of invasion and virulence in the genus Fusobacterium and the proteins that are involved in driving diverse phenotypes in hosts from humans to cattle and sheep. Most of our knowledge comes from a limited number of $F$. nucleatum strains, and a small sampling of outer membrane adhesins that have been experimentally validated as critical for oral interactions, preterm birth and colorectal cancer. The reason for this lack of molecular studies in Fusobacterium is owed to its well known genetic recalcitrance, with only four strains of $F$. nucleatum yielding chromosomal modification (15, 26-28). To aid in our understanding of virulence at the genetic and molecular level, we recently completed nine Fusobacterium genomes and created the FusoPortal database that includes detailed genomic and bioinformatic analysis of this emerging pathogen $(29,30)$. These genomes were used in this study to identify and correct protein 


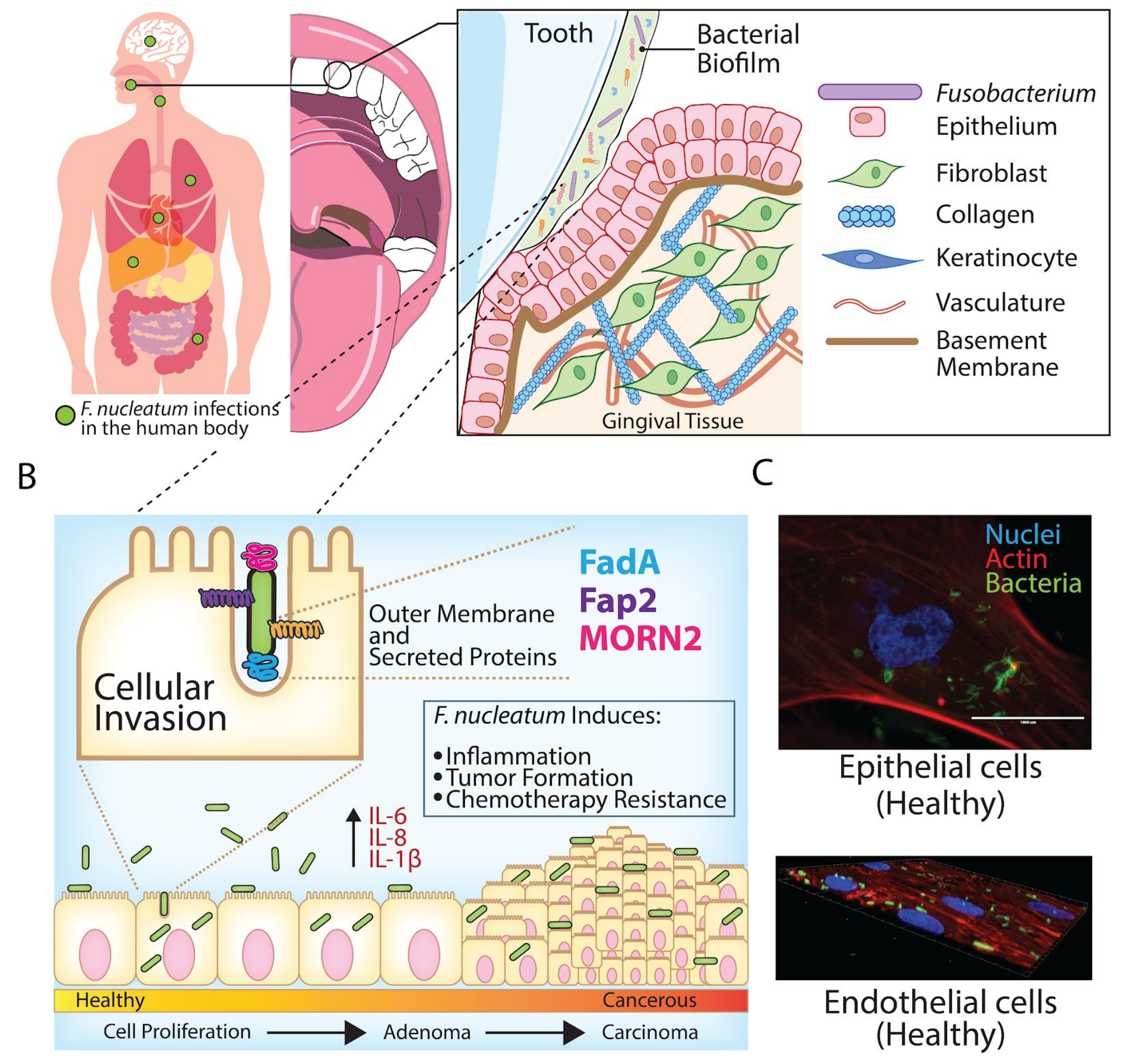

FIG 1 Fusobacterium are invasive opportunistic pathogens capable of multi-tissue colonization and infections. (A) Human bodily locations of characterized Fusobacterium nucleatum infections, with a focus on the oral environment from which this pathogen disseminates throughout the body. (B) Overview of $F$. nucleatum cellular invasion, bioinformatically or experimentally characterized proteins that participate in this phenotype, and consequences of infection within localized tissue niches. (C) Fluorescence microscopy showing $F$. nucleatum subsp. nucleatum ATCC 23726 is highly invasive in both human epithelial and endothelial cells.

families of the autotransporter, FadA, and MORN2 domain containing proteins; all of which are predicted to play key roles in cellular invasion. Among the virulence associated proteins that have been experimentally characterized is Fap2; a large (3786 AA in F. nucleatum 23726), dual-function, autotransporter adhesin that 
binds to the natural killer receptor TIGIT to inhibit tumor cell clearance (30), and initiates host cell docking and altered signaling through the sugar Gal-GalNAc on the surface of colorectal cancer cells $(31,32)$.

FadA is a small ( 125 AA) adhesin that multimerizes on the surface of $F$. nucleatum and has been shown to directly bind to E-Cadherin, where it induces $\beta$-catenin signaling in human cancer xenografts in mice (31). For multiple F. nucleatum genomes we highlight the identification of two homologues of FadA (FadA, FadA2, FadA3), with multiple identical copies of the FadA3 gene being identified and verified throughout each genome (28). FadA is directly involved in host cell binding and invasion in the strain $F$. nucleatum subsp. polymorphum 12230, yet likely due to genetic restraints, has not been characterized in other strains.

In Fusobacterium necrophorum, the leukotoxin LktA (IktBAC operon) is secreted by the Type 5b Two-Partner secretion system, and has been characterized in cattle and sheep infections causing liver abscesses, spontaneous abortion, and foot rot (F. necrophorum subsp. necrophorum) (32, 33). In humans, $F$. necrophorum subsp. Funduliforme is the predominant subspecies and a native inhabitant of the human oropharynx. This strain is leukotoxin positive and causes infections of the throat and jugular vein in the form of the potentially fatal Lemierre's Syndrome (26). Despite our knowledge that LktA induces immune cell toxicity, the mechanisms by which these opportunistic subspecies becomes invasive and establish infection in different organisms is poorly understood. To our knowledge, we have sequenced, annotated, and bioinformatically characterized the only two complete $F$. necrophorum genomes in F. necrophorum subsp. necrophorum ATCC 25286 (34) and F. necrophorum subsp. funduliforme 1_1_36S (29), which are highlighted through experimental characterization of host cell invasion in this study.

Out of the protein families identified and corrected in this study, the most frequent and extensively enriched are the short, repeated, membrane associated protein domains termed MORN2 (membrane occupation and recognition nexus). This expansion of MORN2 domain proteins is highly specific to Fusobacterium (24), with the exception of multiple genes found in Helicobacter bilis which is involved in colitis and hepatitis, as well as infectious abortions in sheep $(35,36)$. No known function has been assigned to the MORN2 domain containing proteins; however most contain signal sequences allowing for export into the periplasmic space and potential further export to the outer membrane or secretion into the extracellular environment.

With the recent development of a selectable gene knockout system in F. nucleatum 23726 (27), the need to identify accurate gene boundaries and surrounding gene clusters will be critical for studying the virulence proteins used by these bacteria to establish infection. We believe this study will provide a critical tool to drive our improvement of genetic manipulation, therefore allowing previously difficult or impossible cloning and recombinant expression of proteins for the development of antibodies and protein structure-function studies. In addition, these data will ultimately help us answer the question of how a genus of Gram-negative bacteria overcomes a lack of multi-protein secretion machinery which are often necessary for bacterial pathogenesis. In summary, the data in this paper provides a foundation for an increased understanding of how Fusobacterium infect a diverse range of host tissues.

\section{RESULTS}

Fusobacterium open reading frame predictions and comparison with previous database annotations. As shown in Fig. S1, the previously completed F. nucleatum subsp. nucleatum ATCC 25586 genome (37) and database depositions of T5aSS proteins were improperly annotated through shortcomings in annotation software, and not errors in the genome. We show that 15 of 15 T5aSS autotransporters, including Fap2 (NP_604343.1: 3165 AA) were previously misannotated (KEGG, Genbank, and UniProt databases) as determined by greatly increased open reading frame length using Prokka (38) and Prodigal (39) and the subsequent identification of the required secretory (SEC) signal sequence for inner membrane translocation. Reannotation of this genome in a previous publication also showed a correction of T5aSS open reading frame annotations (40). To add experimental evidence to our annotations, previous work showed that gene interruption of radD in $F$. nucleatum 23726 resulted in a missing protein band as seen by SDS-PAGE at $\sim 370$ $\mathrm{kDa}$ in F. nucleatum 23726, which matches well with our annotated size of this protein at 3461 amino acids. However, the RadD protein was previously annotated as 2143 amino acids in F. nucleatum 25586, and our new annotation of $3472 \mathrm{AA}$ matches much better with this experimental data validating a protein of $\sim 370 \mathrm{kDa}$. 
This important initial observation led us to reannotate publicly available Fusobacterium genomes to determine if this was a common occurrence. We discovered that multiple genomes suffered from large proteins either being misannotated due to software limitations, or that these large genes spanned the broken boundaries of multi-contig genomes. For example, upon our resequencing and completion of the F. nucleatum subsp. nucleatum ATCC 23726 genome and comparison with the previous 67 contig draft (Fig. 2A), we show that 8 of 15 T5aSS open-reading frames were incorrectly annotated, with four of these being due to contig A

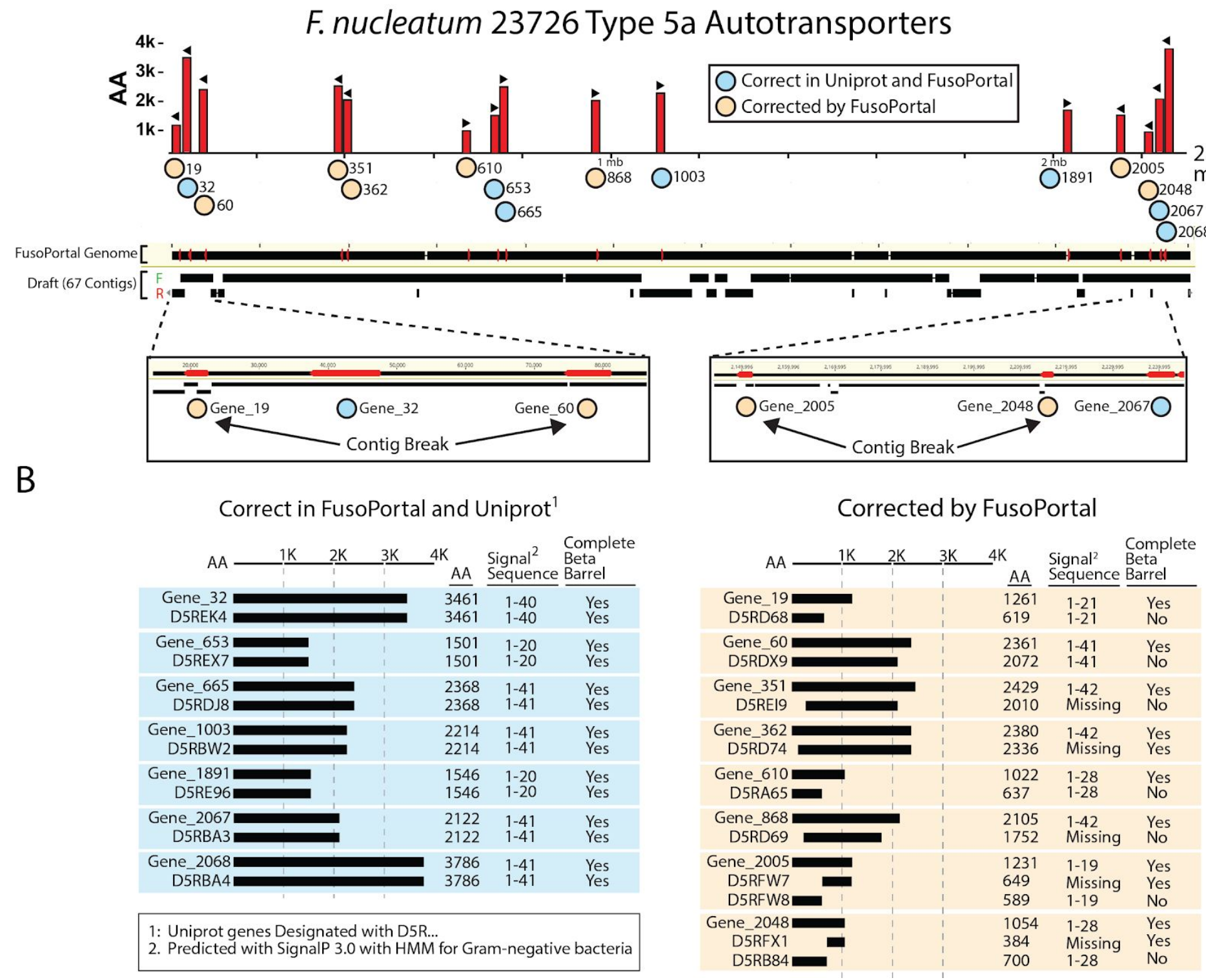

FIG 2 Comparison of T5aSS autotransporter gene annotations from incomplete and complete $F$. nucleatum 23726 genomes. (A) Location (red bar, indicates size in AA) and direction (black arrow) of T5aSS open reading frames in the complete F. nucleatum 23726 genome (NCBI: ASM301978v1) from FusoPortal. Contigs from the draft genome (NCBI: ASM17889v1) were aligned on the complete genome and contig breaks that affected gene annotation are highlighted. (B) Autotransporters that were previously correct (light blue) and corrected (tan) are highlighted and show that annotation errors were a combination of N-terminal (signal sequence) and C-terminal (outer membrane embedding $\beta$-barrel) truncations. 
breaks resulting in fragmented genes. These errors are only partially due to the large gene length $(>11 \mathrm{~kb}$ for fap2), as the other errors were annotation driven (Fig. 2B). Many of these proteins are predicted surface adhesins with homology to Fap2; a key protein involved in F. nucleatum induced colorectal cancer modulation.

We subsequently sequenced and completed a total of nine Fusobacterium genomes and previously showed that genes larger than $3 \mathrm{~kb}$ had a high error rate as was validated in this study for the T5aSS proteins $(29,30,34)$. A comparison of all annotations of T5a-dSS autotransporters for strains $F$. nucleatum 25586 and F. nucleatum 23726 can be found in Table S1. In addition, we provide files containing open reading frames for all virulence proteins discussed in this paper in FASTA format (T5SS, FadA, MORN2)(Text S1), and Table S2 contains a list of all open reading frames with InterPro domains and $\mathrm{N}$-terminal signal sequence validation.

Phylogenetic and protein sequence similarity network analysis of seven Fusobacterium species. Full genome phylogenetic analysis of nine Fusobacterium genomes spanning seven species (Fig. 3A) shows a clear lineage where F. ulcerans, F. varium, and F. mortiferum are distinct from F. nucleatum. Previous analysis had the $F$. necrophorum to $F$. nucleatum phylogenetic relationship more distant than our analysis (23). In the bar graphs in Fig. 3A, we highlight groups of virulence proteins as predicted by Hidden Markov Models (HMM), Interpro analysis, and confirmation that there is a Sec dependent signal sequence. For instance, by pure whole genome phylogenetic analysis, previous studies hypothesized that $F$. necrophorum are passive invaders that can not actively induce uptake into host cells. Upon examination of both $F$. necrophorum genomes, we discovered that $F$. necrophorum 25286 has an expansion of $F$. nucleatum like T5aSS autotransporters that share homology with Fap2, while F. necroporum 1_1_36S has far fewer T5aSS genes, and none of them cluster with Fap2 and its homologues (Fig. 3B). In addition, the non-invasive F. necrophorum 1_1_36S nearly lacks MORN2 (Membrane Ontology and Recognition Nexus Type 2) domain containing proteins, which genomically cluster with T5aSS proteins (24), potentially implicating that these proteins may contribute to an invasive phenotype either directly or indirectly. In addition, F. necrophorum 1_1_36S does not have any FadA genes, where the invasive strains F. nucleatum 23726 and F. necrophorum 25286 have five and four, respectively.

To address limitations in predicting the virulence potential of a bacterial strain using whole genomes, we implemented protein sequence similarity networks to determine if any strains and species shared similarity with previously characterized T5aSS virulence proteins from F. nucleatum (e.g. Fap2, Aim1)(Fig. 3B). To our knowledge, within the Fusobacterium autotransporters, no protein sequence similarity networks (SSN) have previously been reported. In addition, we provide a full phylogenetic tree of all 142 T5aSS autotransproters in Fig S2. We analyzed all T5aSS autotransporters from nine genomes encompassing seven species of Fusobacterium, and show distinct subsets of predicted functions that include surface exposed adhesins, serine proteases, and proteins of unknown function. Within the large adhesins, there is a distinct divide between two subsets of T5aSS adhesins at stringent clustering conditions $\left(10^{-125}\right.$ via EFI-EST)(38). We show that while previous autotransporter analysis broadly clusters RadD with all other Type 5a monomeric autotransporters, this protein associates with a subsection of autotransporters that are more commonly found in multiple copies in $F$. varium and F. ulcerans. Worth noting is the absence of Fap2 like adhesins in $F$. varium, yet supernatants from the colonic mucosa of ulcerative colitis patients were able to induce ulcerative colitis in mice (41). When examining the overall virulence landscape between our analyzed stains of $F$. nucleatum and $F$. varium, there doesn't appear to be much difference when comparing the number of autotransporter, FadA, and MORN2 genes. However, F. varium is not associated with colorectal cancer, and we propose that our analysis of differences in outer membrane adhesin subfamilies could be driving the variation in intestinal disorders associated with each species. Since RadD from $F$. nucleatum clusters with the $F$. varium and $F$. ulcerans adhesins, it remains to be determined if RadD plays a critical role in the cellular invasion or the progression of colorectal cancer associated with $F$. nucleatum. More evidence for this comes from the fact that RadD drives interactions with a diverse set of bacteria (39), and is present in a single copy in the two F. nucleatum strains analyzed. Oddly, F. periodonticum has an expansion of these Fap2 like adhesins, yet has no proteins from the RadD family. To add additional complexity to predicting the function of autotransporters, recent analysis showed that CmpA (Gene_60 in F. nucleatum 23726, FN0254), which clusters near the host binding adhesin Fap2, is a crucial adhesin that binds to Streptococuss gordonii during oral biofilm formation. These observations may prove crucial in our understanding of protein families that drive interaction networks between 
A aCC-BY-NC-ND 4.0 International license.

A

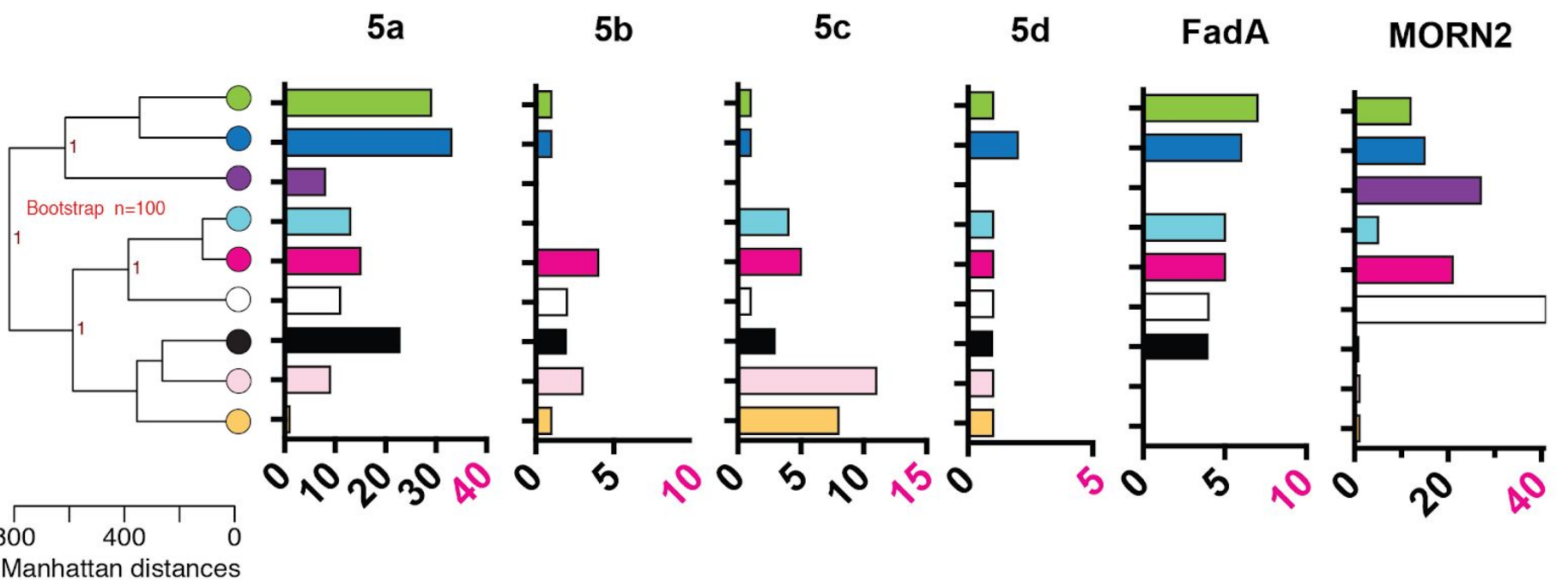

B

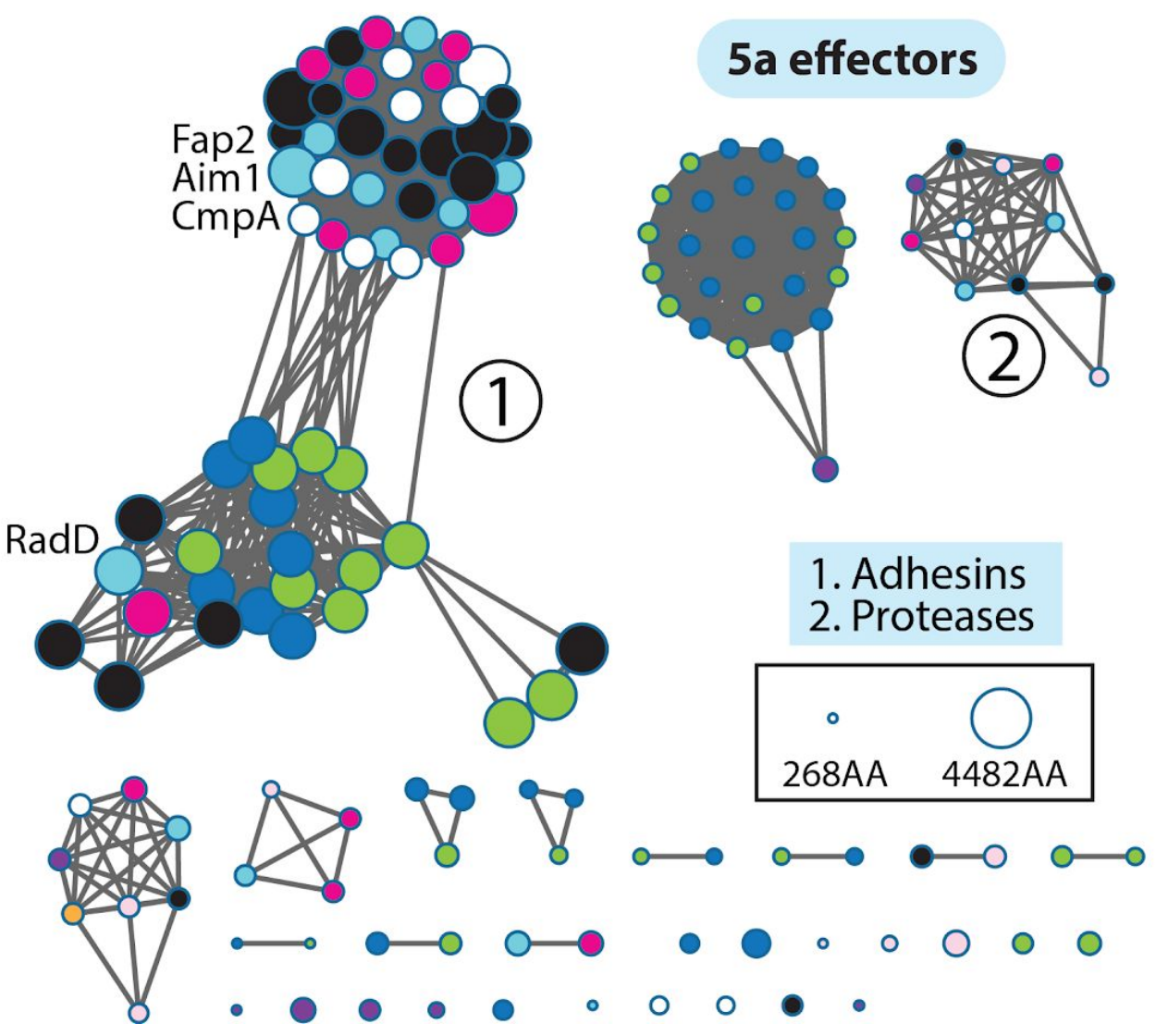

FIG 3 Virulence factor analysis of Fusobacterium. (A) Full-genome phylogenetic tree of seven Fusobacterium species encompassing nine strains. (B) Sequence similarity networks of all T5aSS autotransporters (e-value $10^{-125}$ ) as colored by their designated genomes. Each node represents a single proteins (142 total), and node size represents protein size in amino acids.

the host or competing bacteria in a variety of tissue niches, but provides additional validation that experimental methods are needed to confirm bioinformatic hypotheses.

Comparison of colorectal cancer cell invasion between $F$. nucleatum and $F$. necrophorum. $F$. nucleatum 23726 is a highly invasive strain of Fusobacterium, and we show intracellular bacteria inside Ca9-22 cancerous gingival cells in Fig. 4A. Because the virulence landscapes between F. necrophorum subsp. 
necrophorum 25286, F. necrophorum subsp. funduliforme 1_1_36S and $F$. nucleatum 23726 were strikingly different (Fig. 4B), we tested each strain for the ability to actively invade cancerous colonic epithelial cells (HCT-116). Using imaging flow cytometry, which quantifies the percentage of host cells that are positive for intracellular Fusobacterium (fluorescent outer membrane binding lipid)(Fig. 4C), we show that $F$. nucleatum 23726 is highly invasive, and F. necrophorum 1_1_36S lacks nearly all invasive potential (Fig. 4D). This model fits with previous hypotheses that F. necrophorum are passive invaders. However, F. necrophorum 25286, which has a genetic expansion of $F$. nucleatum-like T5aSS adhesins with homology to Fap2, has significant invasive potential. Our analysis shows that T5aSS effectors are not solely able to predict invasive potential, as $F$. necrophorum 25286 has more genes of this autotransporter protein family than $F$. nucleatum 23726 . Upon further evaluation, we hypothesize that autotransporters, FadA, and MORN2 proteins form cooperative networks that individually contribute to host cell docking and invasion. These results show that a more detailed analysis of invasion using additional strains is warranted, and could help in creating predictive models of invasive potential from genome sequences.

A

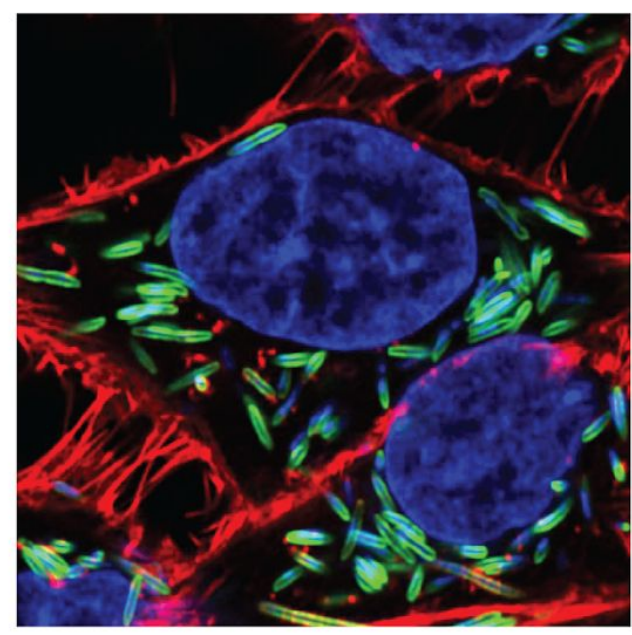

B

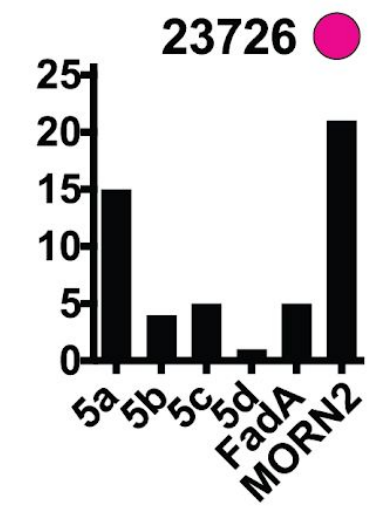

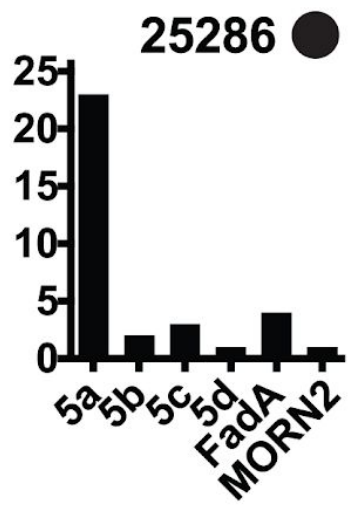

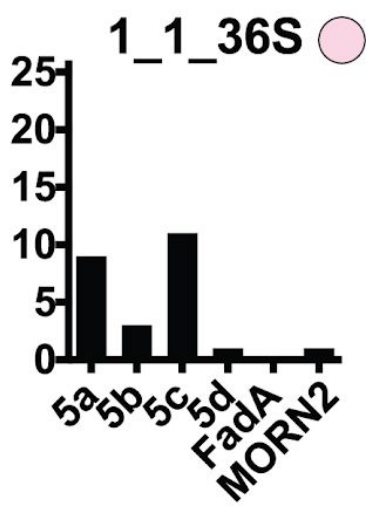

\section{C}

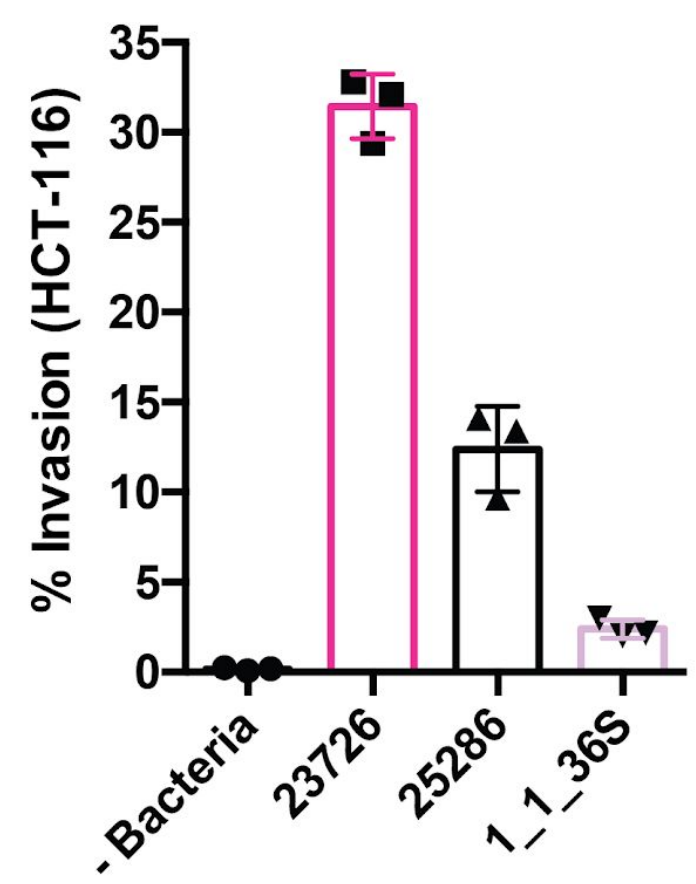

Fig 4 Quantitation of HCT-116 colonocyte invasion by F. nucleatum and F. necrophorum. (A) Super-resolution imaging of intracellular F. nucleatum 23726 in Ca9-22 cancerous gingival epithelial cells. (B) Quantitation of virulence genes in one F. nucleatum (23726 and two F. necrophorum strains (25286, 1_1_36S). (C) Imaging flow cytometry analysis of Ca9-22 cell invasion using fluorescently labeled Fusobacterium. (D) Quantitation of cellular invasion of three Fusobacterium strains using imaging flow cytometry. 
A detailed view of T5SS autotransporters in the genetically tractable strain F. nucleatum 23726. Autotransporters are Gram-negative specific proteins and constitute the largest family of secreted proteins in bacteria (42). Increasing interest in F. nucleatum 23726 has been garnered by several key studies with fap2 gene interruptions $(43,44)$, and the recent development of a double-crossover, markerless gene deletion system for this strain (27). In Fig. 5A, we highlight the basic structure of the four classes of autotransporters (T5a-dSS) that are found in Fusobacterium genomes. F. nucleatum 23726 has 25 total autotransporters (Fig. 5B) ranging in size up to 3786 AA (Fap2), with the majority falling in the classic monomeric T5aSS proteins. Phylogenetic analysis of the T5aSS autotransporters (Fig. 5C) from F. nucleatum 23726 fits well with the multi-genome analysis found in Fig. 3B and Fig. S2. These proteins can bioinformatically be divided into

A

B
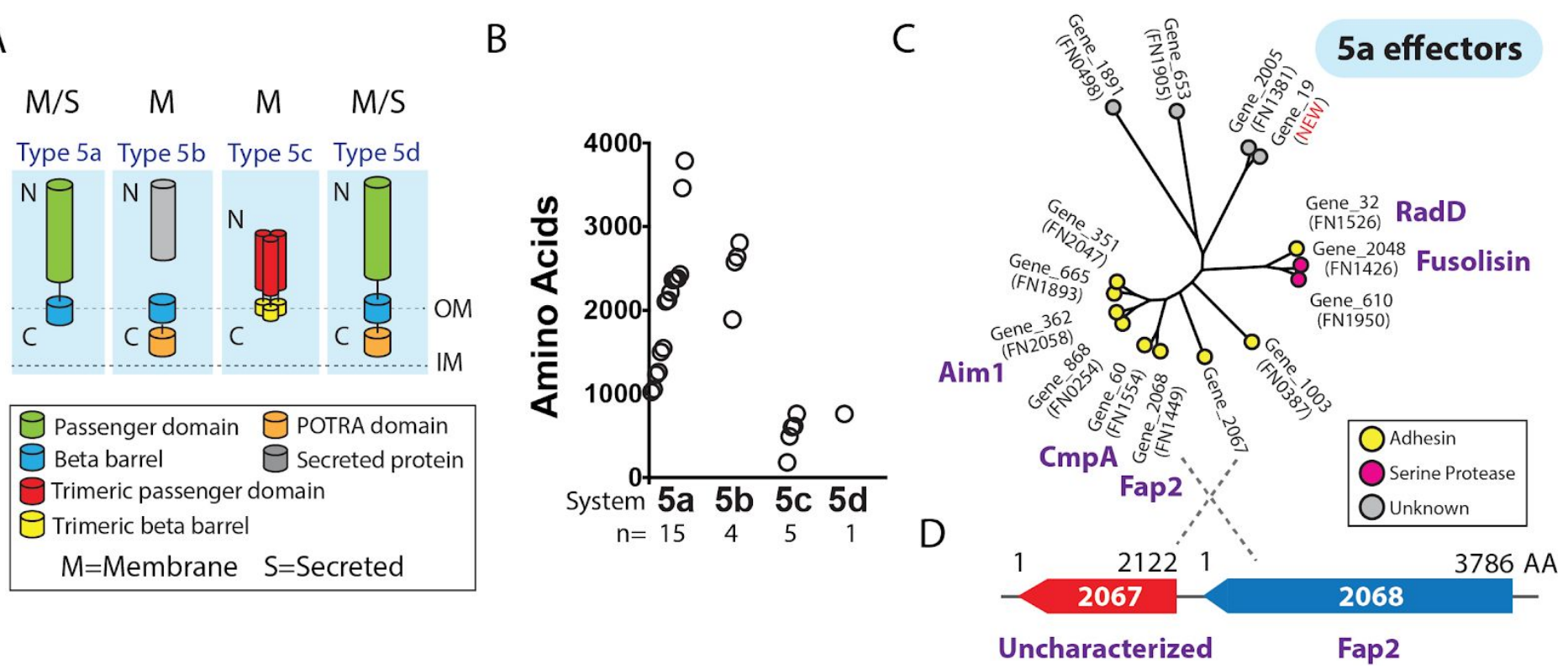

FIG 5 Analysis of T5aSS autotransporters in F. nucleatum 23726. (A) Domain structure of the Gram-negative specific, outer membrane bedded or secreted autotransporter protein family. Type $5 e$ (Intimins) is not represented because Fusobacterium do not contain these genes. (B) Quantities of each family in F. nucleatum 23726, as well as the size in amino acids of each protein. (C) Phylogenetic tree of all 15 T5aSS proteins are divided by node color into predicted protein functions. (D) Highlighting an uncharacterized Fap2 homolog that is just upstream of the well characterized virulence protein Fap2.

three categories based on predicted function and nearest neighbors: adhesins, serine proteases, and proteins of unknown function. We observed that the previously characterized adhesin RadD from F. nucleatum 23726 does not strictly tree near classic adhesins like Fap2 and Aim1, but near the serine proteases that include Fusolisin (FN1426) (39). This could mean that RadD either has an additional uncharacterized function or shares non-enzymatically active motifs with this family. However, a previous study showed that RadD is an arginine-inhibitable adhesin responsible for interspecies bacterial interactions (45). As shown in Fig. 5D we have also identified another T5aSS autotransporter adhesin directly upstream in the $F$. nucleatum 23726 genome, of which there has been no characterization. As this gene is not present in the closely related $F$. nucleatum 25586 genome, further research is needed to determine if this protein plays a cooperative role with Fap2 in host cell invasion.

Our complete F. nucleatum 23726 genome also uncovered a new T5aSS autotransporter (Gene_19) missing in the previous draft assembly. This protein shares strong homology with Gene_2005; previously named FN1381 by the $F$. nucleatum 25586 naming system. Previous bioinformatic analysis of FN1381 in $F$. nucleatum 25586 reported the presence of an ATP- and GTP-binding motif A (P-loop), which currently remains uncharacterized (6). These proteins cluster with multiple autotransporters of unknown function, but could be enzymes based on their phylogenetic locality near the serine proteases. We identified that Gene_19 and 
Gene_2005 (FN1381) are potential gene duplications that have diverged because the C-terminal $\sim 700$ amino acids share $100 \%$ sequence identity.

Discovery and renaming of T5bSS and T5cSS genes in F. nucleatum 23726. As shown in Fig. 6 and Table S1, we have identified four full open reading frames for T5bSS effectors (Two-partner secretion TPS) in F. nucleatum 23726, and the full repertoire of these effectors from the nine Fusobacterium genomes characterized in this study can be analyzed in a phylogenetic tree in Fig. S3. We have renamed the secreted effector genes Type $\mathrm{Vb}$ TpsA ( $v b a A, v b b A, v b c A$, and $v b d A$ ) (Fig. 6A). The paired genes encoding for $\beta$-barrel translocation proteins were renamed Type $\mathrm{Vb}$ TpsB ( $v b a B, v b b B, v b c B, v b d B$ ), and a schematic of TPS architecture is shown in Fig. 6B. The previous draft genome of $F$. nucleatum 23726 had the $\mathrm{VbaA}$ and $\mathrm{VbbA}$ proteins properly annotated, but the $v b c A$ gene was fragmented into two open reading frames. $v b d A$ is a newly identified gene encoding for a 2634 AA protein. These proteins have not been analyzed in any Fusobacterium studies, but other pathogenic bacteria have homologous secreted effectors that contain multiple hemagglutinin domains and function as cytolysins, hemolysins, adhesins, and proteins that initiate contact-dependent growth inhibition (CDI) to fight off neighboring bacteria $(46,47)$. For examples, a T5bSS filamentous haemagglutinin in Bordetella pertussis serves as an adhesin and is essential for colonization of tissues (48). Furthermore, ShIA in Serratia marcescens plays a cytotoxic role by contributing to colonization of tissues (49). Thus, while it remains possible that Type $\mathrm{Vb}$ autotransporters play a role in tissue colonization, they could alternatively be involved in survival and bacterial competition in oral and colorectal niche environments.

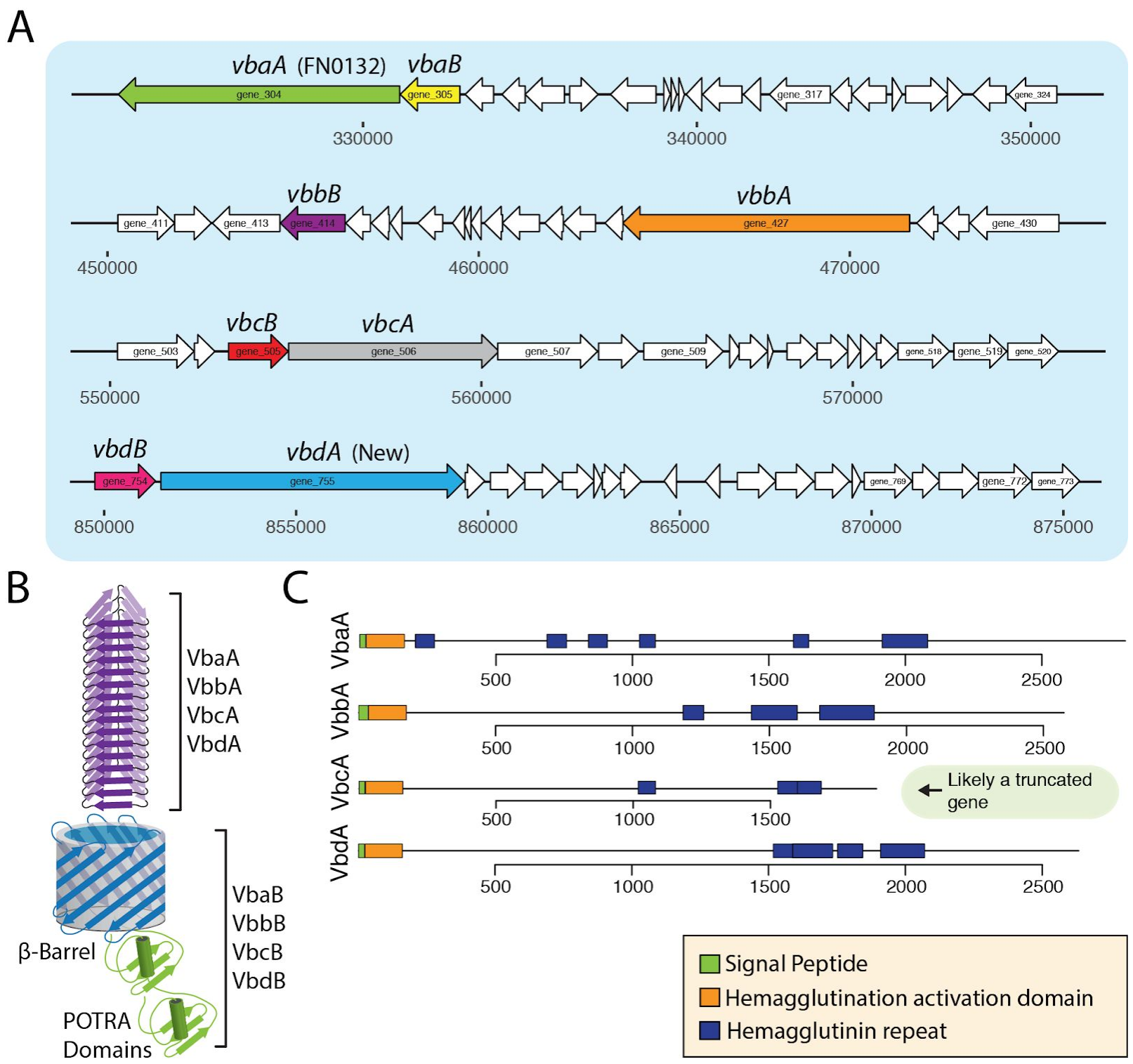


Fig 6 Type 5b secreted proteins (T5bSS) in F. nucleatum 23726. (A) Genomic location and open reading frame sizes for four T5bSS effectors with their respective $\beta$-barrel translocation proteins. (B) Schematic of the secreted $\mathrm{VbaA}, \mathrm{VbbA}, \mathrm{VbcA}, \mathrm{VbdA}$ effector proteins and their respective outer membrane translocation proteins $\mathrm{VbaB}, \mathrm{VbbB}, \mathrm{VbcB}, \mathrm{VbdB}$. (C) Predicted domains of each secreted protein.

In the strain $F$. nucleatum 25586, a previous study revealed that the $\mathrm{N}$-terminal Sec signal sequence was out of frame in T5bSS $\beta$-barrel translocation protein, but the presence of a poly-A stretch that bridged this region in the T5bSS $\beta$-barrel translocation proteins led the authors to propose that slipped-strand translation could occur during phase variation, therefore translating these signal sequence lacking open reading frames into fully functional proteins capable of translocating a T5bSS effector. Our analysis also identified $\beta$-barrel translocation proteins without signal sequences in $F$. nucleatum 25586 . However, in the closely related $F$. nucleatum 23726, all open reading frames for the secreted protein and translocation machinery are in frame and are predicted to allow for protein translation. Because of this discrepancy, all $F$. nucleatum 25586 T5bSS systems don't appear functional, and therefore we haven't included them in our analysis until biochemical characterization proves the slipped-strand translation and expression of these proteins. We have highlighted all potential F. nucleatum 25586 T5bSS genes in Table S1 and Table S2, but note these genes suffer from shifted or in some cases split reading frames.

A

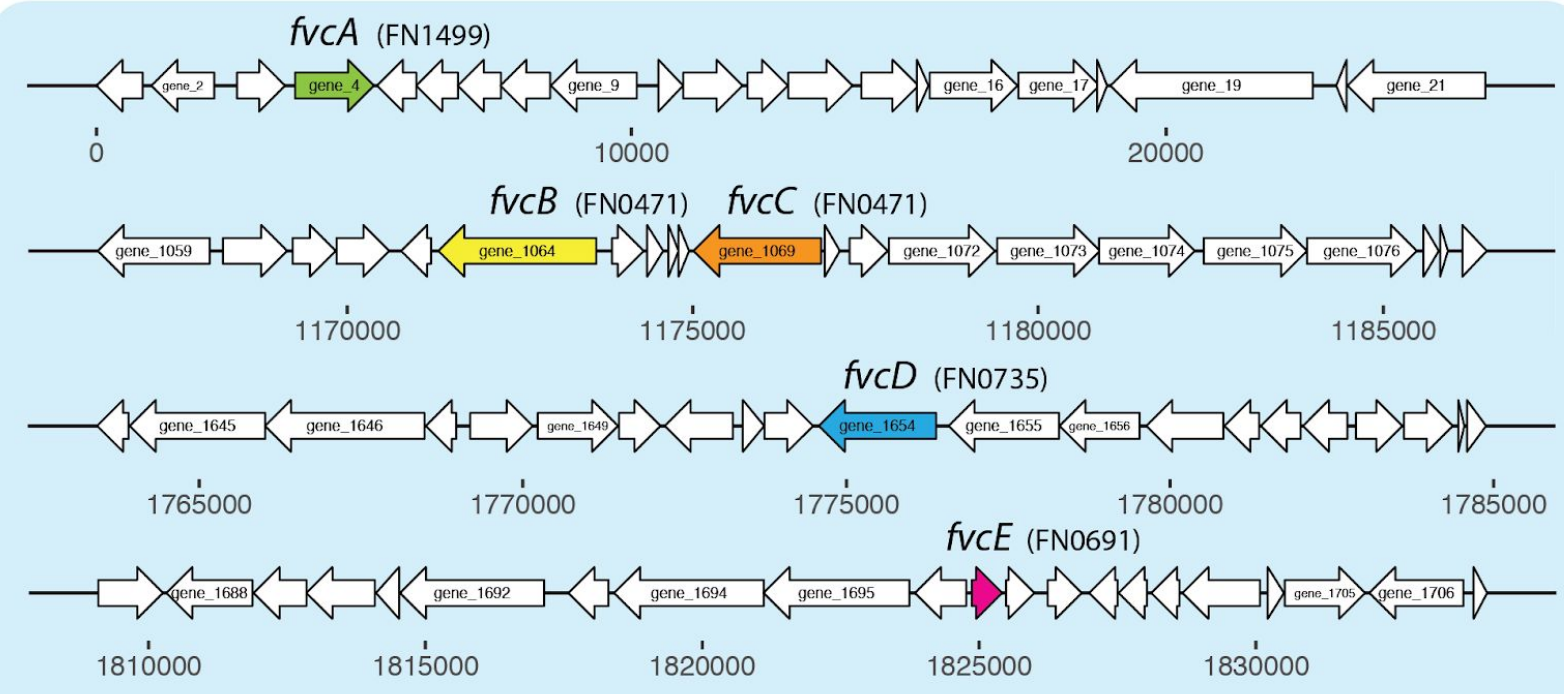

B
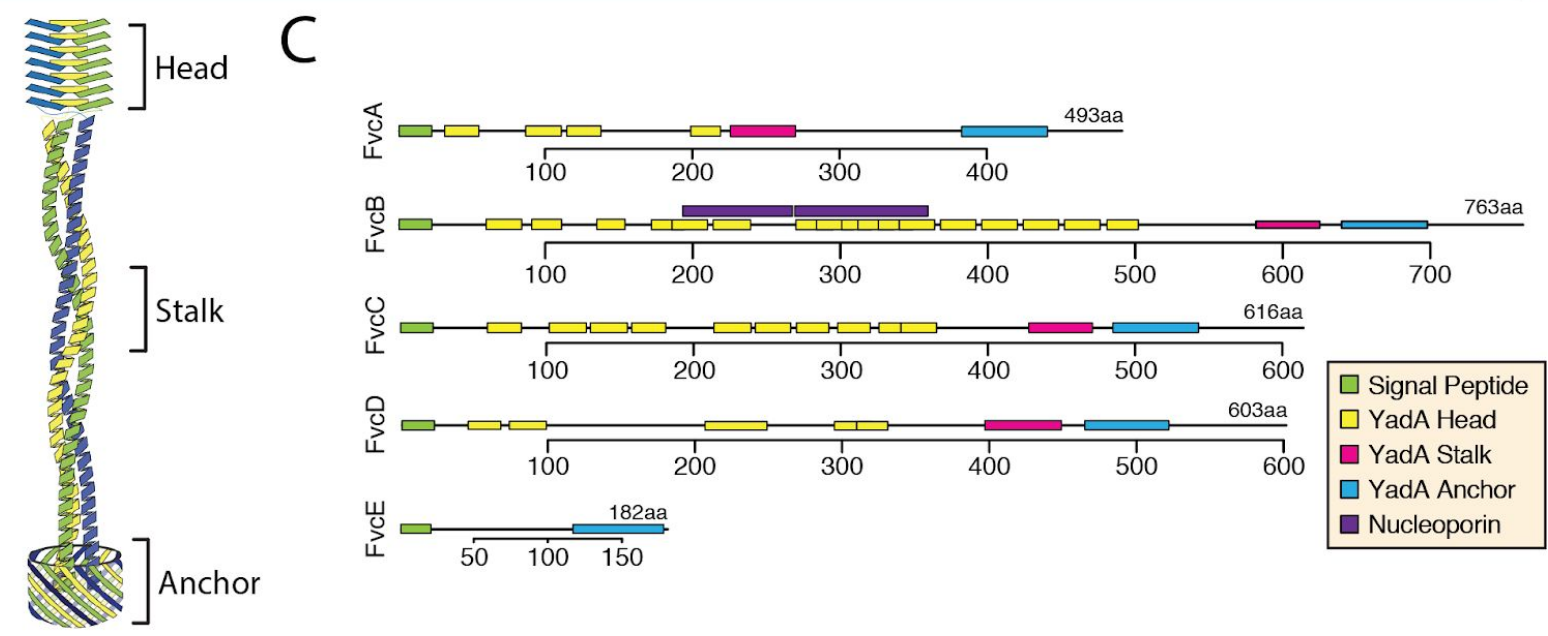

Fig 7 Type 5c secreted trimeric autotransporter proteins (T5cSS) in F. nucleatum 23726. (A) Genomic location and open reading frame sizes for five T5cSS trimeric autotransporter proteins. (B) Schematic of the head stalk, 
and anchor domains. Multiple head domains can be present in one protein. (C) Predicted domains of each each secreted protein.

We report the presence of five T5cSS trimeric autotransporter adhesin (TAA) genes in $F$. nucleatum 23726 as shown in Fig. 7a, and we have renamed them Fusobacterium Type Vc proteins ( $f v c A, f v c B, f v c C$, $f v c D$, and $f v c E)$. Three of the five open reading frames were previously misannotated, with FvcC being the most extreme (new: 615 AA, old: 456 AA). While no TAAs have been studied in Fusobacterium, this protein family consists of important virulence factors in other pathogenic Gram-negative bacteria, including YadA from Yersinia pestis and pseudotuberculosis (13, 50), Hia from Haemophilus influenzae (51), and SadA of Salmonella enterica $(52,53)$. TAAs form long fibrous proteins that can extend for more than $100 \mathrm{~nm}$ from the surface of the bacteria, thereby presenting the adhesive head domains to dock with host cells. YadA binds to the human extracellular matrix proteins fibronectin and collagen, drives invasion into epithelial and phagocytic cells, and inhibits activation of the serum complement (54). In addition to the classic head-stalk-anchor architecture (Fig. 7B), several other domains have been characterized that differentiate the role of TAAs (53). As shown in Fig. 7C, TAAs can have multiple head domains, and the stalk domains are $\alpha$-helical coiled-coils. FvcE, differs in that it is quite small at $181 \mathrm{AA}$, and only contains the required Sec signal sequence and anchor domain. We hypothesized that FvcE could be a non-functioning T5cSS adhesin.

Previous bioinformatic analysis implicated that a genetic expansion in T5cSS autotransporters in less invasive strains indicates that these proteins are likely not used by Fusobacterium for cellular invasion, despite evidence of the TAAs being critical for virulence in multiple human pathogenic Gram-negative bacteria. In Fig. S4, phylogenetic analysis of TAAs from nine Fusobacterium genomes shows that proteins from highly invasive F. nucleatum strains cluster away from those of strains predicted to be less invasive. We propose that TAAs from pathogenic $F$. nucleatum could be playing a role in cellular invasion, and that genetic and biochemical studies need to complement one another before we discount the TAAs as unimportant for Fusobacterium virulence.

Analysis of the FadA protein family. In addition to the Type 5 autotransporters, this current study highlights the unique FadA-like adhesins of Fusobacterium (Fig. 8A-B). Genetic and biochemical studies of FadA in F. nucleatum 12230 showed that this small ( 125 AA) adhesin multimerizes on the bacterial surface and subsequently binds to E-cadherin to modulate endothelial barrier permeability, signaling, and inflammatory responses in models of human cancer (55) This implicates FadA in the entry and exit of blood vessels to translocate $F$. nucleatum to the fetal-placental unit where multiple studies support a role for this bacterium in preterm birth $(56,57)$. Our phylogenetic data (Fig. S6) show that multiple fadA-like adhesin genes are present across Fusobacterium species, where invasive strains possess a higher number and diversity of these proteins. By contrast, the passive invaders F. necrophorum 1_1_36S and F. gonadioformans 25563 lack the entire FadA protein family. This newly found FadA profile of $F$. nucleatum warrants further investigation into the invasive potential and function of these paralogs which we have named FadA, FadA2, FadA3a, FadA3b, FadA3c; with the FadA3 proteins being complete gene triplications that are $100 \%$ identical at the amino acid level (Fig. 8C). The FadA3a-C genes were also found in F. nucleatum 25586, as shown by phylogenetic analysis in Fig. S6, but were not found in triplicate in the other seven Fusobacterium strains analyzed. We validated that these genes were in fact correct annotations and not genome errors using PCR with primers designed for unique upstream regions of each gene in F. nucleatum 23726 (Fig. 8D, Fig. S7) 
bioRxiv preprint doi: https://doi.org/10.1101/534297; this version posted January 29, 2019. The copyright holder for this preprint (which was not certified by peer review) is the author/funder, who has granted bioRxiv a license to display the preprint in perpetuity. It is made available under aCC-BY-NC-ND 4.0 International license.

A

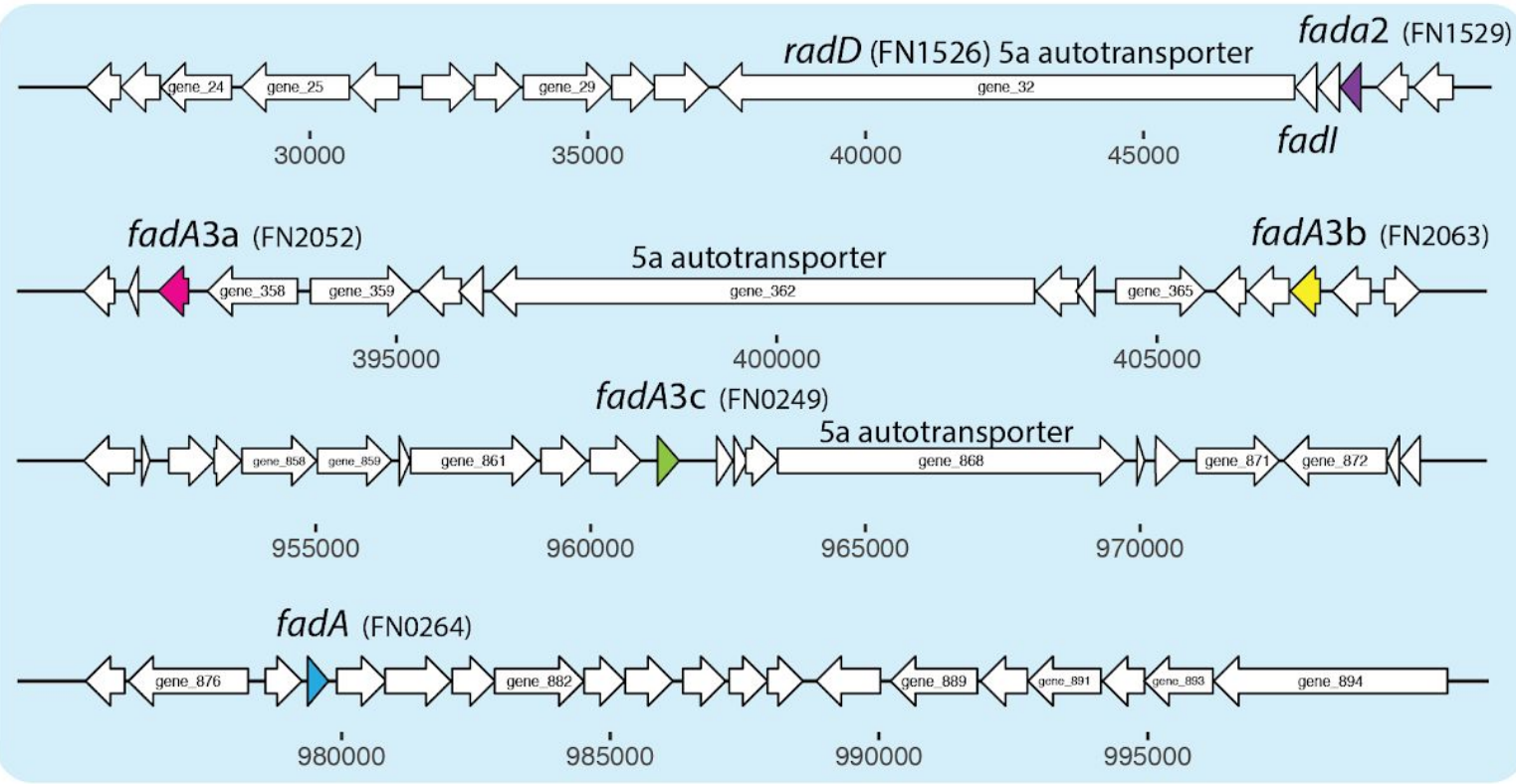

B

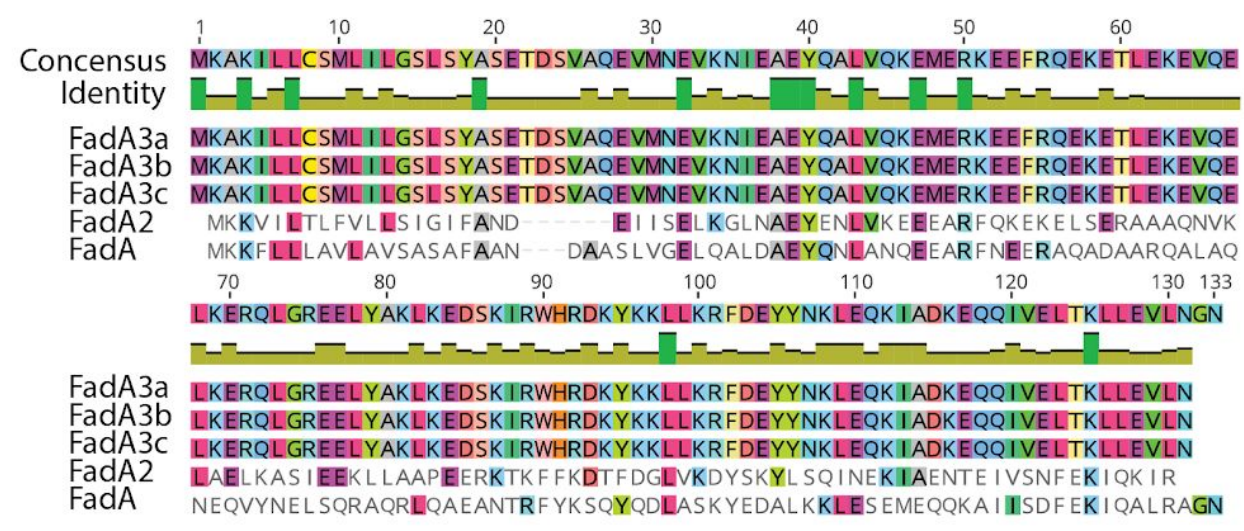

C
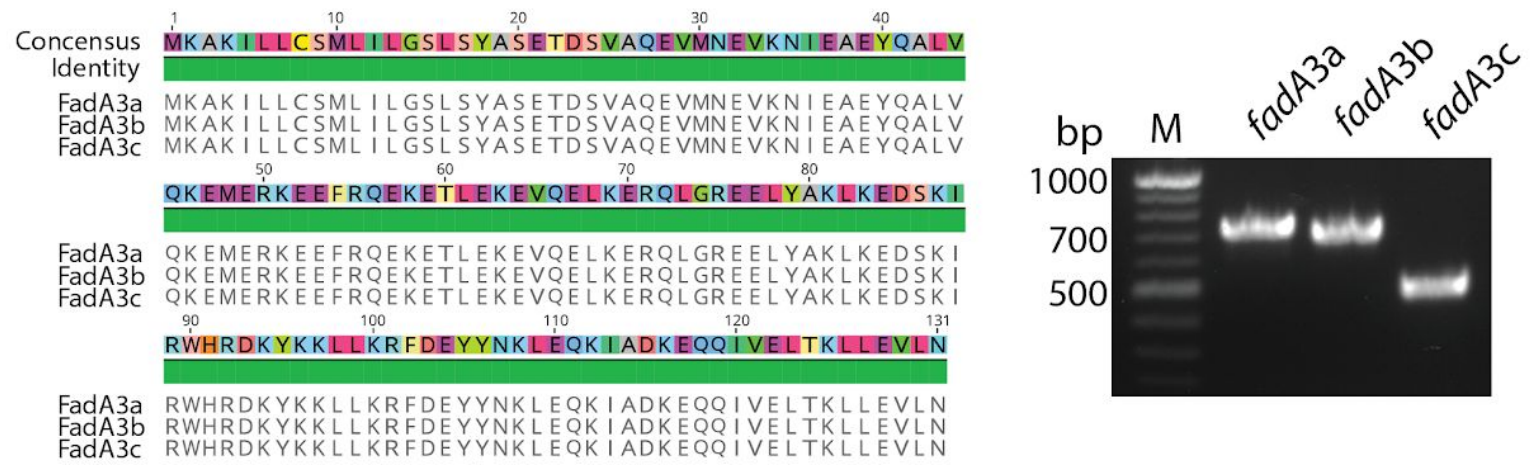

Fig 8 FadA family proteins in F. nucleatum 23726. (A) Genomic location and open reading frame sizes for five FadA family proteins. (B) CLUSTAL alignment of FadA proteins from F. nucleatum 23726. (C ) CLUSTAL alignment of FadA3a, FadA3b, FadA3c shows $100 \%$ sequence identity at the amino acid level. (D) PCR to confirm the presence of the $\mathrm{fad} A 3 \mathrm{a}, \mathrm{fad} A 3 \mathrm{~b}, \mathrm{fad} A 3 \mathrm{c}$ genes at distinct locations in the genome of $F$. nucleatum 23726. 
Towards understanding the role of MORN2 domain proteins in Fusobacterium virulence. Genomic studies have greatly detailed the expansion of MORN2 domain-containing proteins in Fusobacterium, with the greatest enrichment in the bioinformatically predicted active invaders (24). Despite a great interest in their role in invasion, to our knowledge, no studies have been reported that show a direct role for this hypothesis. In Fig. S8 we generated a protein tree for 120 MORN2 domain containing proteins from nine Fusobacterium genomes. We show in Fig. 3a that $F$. periodonticum contains more than 40 MORN2 domain proteins, which is twice as many as the two validated invasive F. nucleatum strains.

MORN2 domain-containing proteins could enhance adhesive and active invasive traits as these genes clustered near, FadA, RadD, and additional T5aSS autotransporter adhesins. Since this study, a role for these proteins in interspecies interactions has been suggested (15), as they are predicted surface-associated proteins and some of them are part of the 'FusoSecretome' (58). More recently, MORN2 domain containing proteins were found secreted into $F$. nucleatum outer membrane vesicles (59). In addition, the fact that these proteins possess a YwqK domain suggests that they could be acting as toxin-antitoxin systems for interspecies competition or as a bacterial abortive infection systems that limit viral replication and are activated by phage infection (60).

\section{DISCUSSION}

Fusobacterium are opportunistic pathogens that cause diverse infections and show strong correlations with multiple diseases in humans and higher mammals (15). F. nucleatum has garnered significant attention as an 'oncobacterium' that contributes to the progression and severity of colorectal cancer, and has also been implicated in malignant oral leukoplakia (61) and oral squamous cell carcinoma $(62,63)$. As an oncomicrobe, $F$. nucleatum infection studies have shown that administration of the antibiotic metronidazole reduces tumor burden in human tumor generated xenografts in mice (22). As antibiotic therapy to treat disease could result in altered gut flora that changes the efficacy of chemotherapy drugs, a new paradigm would be to control infections at the disease site without antibiotics, or the opportunity to block this pathogen from leaving its native human oral cavity. For $F$. necrophorum, mostly of the subspecies funduliforme, infections of the jugular vein and subsequent progression to Lemierre's Syndrome are often fatal in humans. F. necrophorum subsp. necrophorum is the primary causative agent of bovine hoof rot and liver abscess, causing severe monetary loss in the livestock industry. The differences in F. nucleatum and $F$. necrophorum virulence and disease association is not well understood. We highlight that both $F$. necrophorum 25286 and $F$. necrophorum 1_1_36S both encode for the LktA leukotoxin that induces the activation and apoptosis of leukocytes $(64,65)$. The IktBAC operon responsible for the production of this T5bSS secreted toxin is absent in all other strains of Fusobacterium analyzed, and could explain the severe abscess phenotype induced by this species.

There have been several bioinformatic studies of Fusobacterium, but none of these used databases that were entirely populated with complete genomes. This lack of complete genomes led us to sequence, assembly, annotate, and create the FusoPortal database (29) of Fusobacterium genomes to aid in the bioinformatic and molecular experiments found in this study. These data provide highly accurate gene boundaries, and therefore will greatly facilitate the design and production of recombinant proteins for structural and functional studies; an area that is severely lack in the Fusobacterium field. Our data confirmed that Fusobacterium are unique in that they lack all large protein secretion machinery of the Type 1,2,3,4, and 6 varieties, yet they are still opportunistic pathogens. However, a recent proteomic analysis of Fusobacterium nucleatum revealed that secreted outer membrane vesicles consist of proteins from of each of the virulence factor families we analyzed in this study (57).

We show the importance of having accurate and complete genomes in identifying large proteins; the majority being Type 5 secreted proteins that have been characterized as virulence factors in a wide range of Gram-negative bacteria. As we have seen the importance of a single protein in $F$. nucleatum virulence in the outer membrane adhesin Fap2, it will be important to not overlook proteins of this size merely because incomplete genome assembly results in open reading frame fragmentation. A key contribution of this work is the identification of Fap2 homologues in multiple Fusobacterium genomes, with a focus that $F$. necrophorum subsp. necrophorum 25286 has two close homologues of this adhesin. As this subspecies of $F$. necrophorum 
is associated with serious livestock infections, this data, combined with the potential to perform genetic manipulation in these strains, could lead to a more effective live, attenuated vaccine for bovine hoof rot and liver abscesses. In addition, now that all large outer membrane autotransporters have been identified in multiple $F$. necrophorum strains, there is an opportunity to develop new protein-based vaccines from this proven immunogenic protein family (pertactin, Bordetella pertussis, whooping cough vaccine)(66). In Orientia tsutsugamushi, the autotransporter ScaA acts as a critical bacterial adhesion factor. Animal models have shown that anti-ScaA antibodies have proven to be the most promising trial of scrub typhus vaccination (67). Finally, The T5aSS autotransporter Hap from Haemophilus influenzae has been studied as a potential vaccine target for the prevention of nontypeable $H$. influenzae disease $(68,69)$.

While we know that Fusobacterium contribute to several diseases, our understanding of the overarching molecular mechanisms driving the virulence of these bacterial species remains limited. We focused our virulence factor analyses on the Type 5 autotransporters, FadA adhesins, and MORN2 domains protein families. We briefly state that to our knowledge, the role of T5bSS (Two-partner secretion), T5cSS (trimeric autotransporters), and MORN2 domain proteins in Fusobacterium have no published functional studies, and therefore represent an exciting future field to pursue. Not analyzed in this study, Fad-I is an outer membrane protein that was shown to induce human beta defensin 2 (hBD-2) through a toll-like receptor mediated host response. The immune modulation induced by Fad-I in F. nucleatum strains 23726 and 25586 was far more potent than that seen in F. nucleatum 10953 (70). As with all protein families, this is a great example of how small sequence variations in key proteins could account for altered virulence between phylogenetically similar strains of Fusobacterium.

Type 5a secreted autotransporters are virulence factors in a broad range of Gram-negative pathogens but appear to rely heavily on an expansion of T5SS effectors for host colonization and infection. F. nucleatum in the oral cavity serves as a bridge for bacteria-bacteria aggregation, and interactions with mammalian cells and inert tooth surfaces within the gingival pocket (71). The T5aSS proteins RadD and Fap2 are critical for inter-species adherence and the overall architecture of multispecies biofilms $(43,45)$. Therefore, Type $5 a$ autotransporters play key roles in co-aggregation, cell-cell interaction, and biofilm formation during healthy and pathogenic states. Our data suggest that newly identified subsets of T5aSS auotransporters are present in a variety of Fusobacterium species, and therefore new genetic and biochemical studies should be designed to characterize these proteins in virulence.

While Fusobacterium have been reported as non-motile, we seeked to determine if $F$. nucleatum T5aSS autotranspoters share homology with IcsA from from Shigella flexneri, or T5cSS proteins with BimA from Burkholderia species, as these proteins localize to a single bacterial pole (old pole) and coordinate intracellular actin based motility $(72,73)$. Using our custom BLAST server that is built into the FusoPortal database, we show no homology to IcsA and low homology to the membrane associated $\beta$-barrel of BimA. These data agree well with a lack of actin based motility reported by all previous studies and our own observation of intracellular F. nucleatum. Despite not using actin-based motility for intracellular movement, another intriguing observation was that actin localizes to intracellular $F$. nucleatum in human keratinocytes (74), and that inhibition of new actin synthesis blocked intracellular entry (74). The protein or proteins involved in this direct or indirect actin recruitment have yet to be identified. Determining if intracellular $F$. nucleatum cloak themselves or a host vacuole in actin to evade host clearance through ubiquitination and xenophagy, as seen for Listeria monocytogenes and Chlamydia trachomatis $(75,76)$, could be a key piece in understanding the intracellular persistence and dissemination of this pathogen.

The identification of up to six FadA family proteins in a genome leads us to hypothesize that there is cooperativity among this protein family, and that the FadA homologues, FadA2 and FadA3, could have similar functions as adhesins, but have unidentified host receptor molecules. In F. nucleatum 12230, a $\Delta$ fadA mutant shows greatly reduced proliferation of human cancer cells (HCT-116, HT29), but this pro-carcinogenic phenotype was recovered by fadA complementation and the addition of purified active FadA to cell cultures. In addtion, FadA is also important for the colonization of $F$. nucleatum 12230 in mouse placenta (77). With five FadA family proteins in the genetically tractable F. nucleatum 27326 , it will be key to delete multiple copies of these proteins to determine if they act synergistically during infection, or if FadA, FadA2, and FadA3 play distinct roles in virulence and colonization in diverse tissue niches including the subgingival microbial community, human placenta, or the colon. 
In conclusion, we provide bioinformatic identification and analysis of virulence factors, as well as host-pathogen infection studies to dissect the role of this landscape in cellular invasion. We hypothesize that autotransporters, FadA, and MORN2 proteins synergistically form a host cell docking and invasion network that confer the host, tissue, and disease mechanism of the diverse range of Fusobacterium species. These results show that a more detailed analysis of invasion using additional strains is warranted, and could help in creating more accurate predictive models of invasive potential from genome sequences. This study will benefit from future work that expands upon our nine genome analysis to include additional Fusobacterium species and clinical strains, which will ultimately lead to a deeper understanding of individual proteins in disease. It is our hope that these genomes, bioinformatic analyses, and Fusobacterium invasion studies spark the discovery of new virulence factors and drive studies that further our understanding of virulence mechanisms at the molecular level in the diverse bacterial genus of Fusobacterium.

\section{MATERIALS AND METHODS}

\section{Use of genomic information for bioinformatic analysis of nine Fusobacterium strains}

Fusobacterium genomes and all associated data used for this study can be accessed under the NCBI BioProjects PRJNA433545 and PRJNA513186. Annotations for all genes were performed with Prodigal (39) or Prokka (38), and can be found on the FusoPortal website (http://fusoportal.org) or our Open Science Framework data repository (http://osf.io/2c8pv). In addition, $\mathrm{NCBI}$ annotated each genome using their Prokaryotic Genome Annotation Pipeline. Signal peptide prediction was done with SignalP 3.0 and the HMM option (78). Protein functions were predicted using Interpro analysis (79) within Blast2GO 5.2.5 software (80), and predictions for all virulence proteins used in this study can be found in Table $\mathbf{S 2}$.

\section{Protein sequence similarity networks (SSN)}

Networks were created by identifying all protein families of interest using the Interpro server within Blast2Go software. Protein hits were manually checked for accuracy and the presence of a Sec signal sequence.. Qualifying proteins were then analyzed using the all-vs-all BLAST feature within the EFI-EST server (81), followed by cluster mapping in Cytoscape 3.0 (82). All raw files for proteins in fasta format, as well as Cytoscape networks, are posted in our Open Science Framework repository.

\section{Phylogenetic analysis of Fusobacterium genomes}

Full genome phylogenetic analysis of nine Fusobacterium genomes (Fig. 3A) was performed using the MicroPan (83) R-package of pan-genome analysis. All protein open reading frames for each genome were included in the analysis. Nodes for each protein were manually colored in Adobe Illustrator to match the genome key depicted in Fig. 3B.

\section{Phylogenetic analysis of virulence factors}

Protein trees (Fig. S2-6, S8) were built within Geneious 9.02 using the Geneious Tree Builder. Pairwise alignment was run using a Blosum62 cost matrix and neighbor-joining trees were built using a Jukes-Cantor genetic distance model. Nodes for each protein were manually colored in Adobe Illustrator to match the genome key depicted in Fig. 3B.

\section{Cellular infections of $\boldsymbol{F}$. nucleatum in epithelial and endothelial cells.}

A single colony was used to start overnight cultures of $F$. nucleatum 23726, $F$. necrophorum 25286 , or $F$. necrophorum 1_1_36S. Stationary phase cultures were back-diluted to $\mathrm{OD}_{600}=0.1$ in $2 \mathrm{mLs}$ of Columbia Broth supplemented with hemin and vitamin $\mathrm{K}(\mathrm{CBHK})$ and grown to exponential phase $\left(\mathrm{OD}_{600}=0.4\right)$. Fusobacterium cultures were then transferred to a $1.5 \mathrm{~mL}$ conical tube and centrifuged at 5,000 rcf for 3 minutes to pellet bacterial cells. CBHK was removed and the bacterial cell pellet was resuspended in $100 \mathrm{uL}$ of PBS, $\mathrm{pH} 7.4$, and incubated in $500 \mathrm{ng}$ FM 1-43FX membrane probe for 5 minutes. Bacteria were centrifuged at 5,000 rcf for 3 minutes, and the cell pellet was washed with PBS, centrifuged at 5,000 rcf for 3 minutes, and the cell pellet was resuspended in $1 \mathrm{~mL}$ of PBS $\mathrm{pH}$ 7.4. Next, Fusobacterium were added (MOI 10:1) to the media of confluent human cell monolayer cultures in 6 well plates (for imaging flow cytometry) or \#1.5 coverslip bottom 
plates (fluorescence microscopy), and incubated for 1 hour at $37{ }^{\circ} \mathrm{C}$ in $5 \% \mathrm{CO}_{2}$. Following infection, epithelial cells were washed two times with cell culture media and the extracellular bacteria were killed by incubating epithelial cells with cell culture media supplemented with penicillin/streptomycin for 30 minutes. Post infection, cells were either analyzed by fluorescence microscopy or analyzed by imaging flow cytometry as described in the following sections.

\section{Fluorescence microscopy of intracellular F. nucleatum in FHC colonocytes and Ca9-22 gingival cells}

In Fig. 1C (top panel), a confluent monolayer of FHC healthy colonocytes (ATCC CRL-1381) were grown in DMEM:F12 medium supplemented with 10\% FBS (Atlanta Biologicals) in \#1.5 coverslip glass bottom plates. Cells were infected in antibiotic free DMEM:F12 media with a 10:1 MOI of $F$. nucleatum 23726 labeled with the fluorescent lipid $\mathrm{FM} 1-43 \mathrm{FX}$ were for one hour at $37^{\circ} \mathrm{C}$ in $5 \% \mathrm{CO}_{2}$. Extracellular bacteria were then killed with DMEM:F12 supplemented with $100 \mathrm{I} . \mathrm{U} . / \mathrm{mL}$ penicillin and $100(\mu \mathrm{g} / \mathrm{mL})$ streptomycin. After washing with media, cells were fixed in well with PBS 3.7\% paraformaldehyde, and permeabilized with $1 \%$ Triton X-100. Cells infected with $F$. nucleatum 23726 were then stained with $1.0 \mu \mathrm{g} / \mathrm{ml}$ DAPI (Invitrogen) to visualize DNA and Texas Red-X phalloidin for F-actin filaments (Thermo Fisher). Images were acquired using a 63X oil objective on an EVOS FL fluorescent microscope.

In Fig. 4A, Ca9-22 cancerous gingival cells were used for invasion with F. nucleatum 23726. Growth and infection conditions were the same as for the HCT-116 cells above with the exception that the culture media was MEM/EBSS with $10 \%$ FBS. Images were acquired using a $60 \mathrm{X}$ objective on a Zeiss 880 Airyscan equipped fluorescent microscope.

\section{Fluorescence microscopy of intracellular F. nucleatum HVMEC endothelial cells}

In Fig. 1C (bottom panel), HVMEC Adult Dermal Cells (Lonza) were cultured in a custom-built 3D printed chamber where a \#1.5 coverslip was adhered to the bottom of the printed well using biocompatible polydimethylsiloxane ((PDMS) SYLGARD 184 Silicone Elastomer Kit). The CAD model of the micro-chamber was designed using Autodesk Inventor Professional 2018. The chamber was printed with PLA using MakerBot Ultimaker 2. . Additionally, cell attachment factor (Cell Systems) and a thin lining of collagen (5mg/mL) were coated on the coverslip before seeding the host cells within the wells. HVMEC cells were grown in EGM MV-2 (Lonza) media at $37{ }^{\circ} \mathrm{C}$ in $5 \%$ CO2. Cells were infected in antibiotic free DMEM:F12 media with a 10:1 MOI of F. nucleatum 23726 labeled with the fluorescent lipid FM 1-43FX were for one hour at $37{ }^{\circ} \mathrm{C}$ in $5 \% \mathrm{CO} 2$. Extracellular bacteria were then killed with DMEM:F12 supplemented with $100 \mathrm{I} . \mathrm{U} . / \mathrm{mL}$ penicillin and 100 $(\mu \mathrm{g} / \mathrm{mL})$ streptomycin. After washing with media, cells were fixed in well with a $10 \%$ formalin solution. The fixed cells were washed with phosphate buffer solution (PBS) and blocked with a solution of PBS-X containing 10 $\mathrm{mL}$ PBS, $5 \mu \mathrm{L}$ Triton-X, and $200 \mathrm{mg}$ Bovine Serum Albumin (Fisher BioReagents). After rinsing with PBS, the cells were stained with Alexa Fluor 568 phalloidin (Life Technologies) for F-actin filaments (1:100 Dilution) and $1.0 \mathrm{\mu g} / \mathrm{ml}$ DAPI (Invitrogen) for the nucleus. Imaging was performed using a Zeiss LSM 800 Confocal Microscope. Representative images and z-stacks were obtained using a Zeiss 63x 1.8 NA oil immersion lens with $4 x$ averaging.

\section{Imaging Flow Cytometry and quantitation of Fusobacterium invasion into HCT-116 cells}

At the end of two hour Fusobacterium infections, adherent HCT-116 cancerous human colonocytes were gently removed from tissue culture treated plates by incubating with $0.05 \%$ trypsin for 5 minutes and subsequently transferred to a $1.5 \mathrm{~mL}$ conical tube. The trypsin was then quenched with $1 \mathrm{~mL}$ of cell culture media supplemented with penicillin/streptomycin and 10\% FBS Cells were centrifuged at 1,000 g for 3 minutes. Pelleted epithelial cells were then fixed by incubating in 3.2\% paraformaldehyde for 15 minutes. Following incubation, the cells were centrifuged at $1,000 \mathrm{~g}$ for 3 minutes, and pelleted cells were washed one time with 1 $\mathrm{mL}$ of PBS $\mathrm{pH}$ 7.4. Cells were then centrifuged at $1,000 \mathrm{~g}$ for 3 minutes and resuspended in $30 \mu \mathrm{L}$ of PBS $\mathrm{pH}$ 7.4 and visualized using AMNIS ImageStream Mark II instrument. For each data set in triplicate, $\geq 1000$ individual cells were selected by selective gating applied to all data sets, and \% invasion was determined by dividing the number of FITC channel positive cells by the total number of cells.

\section{PCR to validate the presence of three separate genes for fadA3a-c in F. nucleatum 23726}


Genomic DNA was extracted from exponential phase F. nucleatum 23726. Primers as shown in Fig. $\mathbf{S 7}$ are prDJSVT1006-1009. The following 5'-3' correspond to each: prDJSVT1006; 5'

CTAAACTCTTCCTTTCTTTCCATTTCC 3', prDJSVT1007; 5' CCTATCAGGAAGTATGATAACTTTAACAAG 3', prDJSVT1008; 5' CCTATACCCTAGCAAACAATAACAAAGTC 3', prDJSVT1009; 5'

GAACATGAAATAAGACAAATATTTTAAGGATG 3'. PCR was run using Q5 polymerase (NEB) and a 50-62

${ }^{\circ} \mathrm{C}$ annealing temperature gradient. Products were visualized using $1 \%$ agarose gels stained with ethidium

bromide.

Data availability. All genomic data used for protein annotation can be found on NCBI under BioProjects PRJNA433545 and PRJNA513186. All associated raw data outside of supplemental materials, which includes the T5aSS autotransporer protein similarity network can be found on our our Open Science Framework data repository (https://osf.io/vs3fd/?view_only=1752886f47234a6e900f75b73b72fe56 )

\section{SUPPLEMENTAL MATERIAL}

Supplemental material for this article may be found online

FIG S1
FIG S2
FIG S3
FIG S4
FIG S5
FIG S6
FIG S7
FIG S8
TbI S1
Tbl S2
Text S1

\section{ACKNOWLEDGMENTS}

This article has been supported by the National Science Foundation Career Award CBET-1652112 (Verbridge), a Commonwealth Health Research Board Award 208-10-18 (Slade), and the USDA National Institute of Food and Agriculture (Slade). We would like to thank the following for technical assistance with experiments: Kristi Decourcy from the Fralin Life Sciences for assistance with microscopy; Melissa Makris from the Virginia-Maryland School of Veterinary Medicine for imaging flow cytometry. We thank Virginia Tech's Open Access Subvention Fund for publication funding. 
SUPPLEMENTAL FIGURES. Umana et al. 2019.

\begin{tabular}{|c|c|c|c|c|}
\hline Gene & KEGG AA & Signal? & Prodigal AA & Signal? \\
\hline FN0254 & 1677 & NO & 2105 & $1-42$ \\
\hline FN0387 & 1724 & NO & 2214 & $1-42$ \\
\hline FN0498 & 583 & NO & 1536 & $1-20$ \\
\hline FN1381 & 1176 & NO & 1231 & $1-19$ \\
\hline FN1426 & 961 & NO & 1027 & $1-64$ \\
\hline FN1449 (fap2) & 3165 & NO & 3738 & $1-41$ \\
\hline FN1526 & 2143 & NO & 3472 & $1-40$ \\
\hline FN1554 & 1582 & NO & 2361 & $1-41$ \\
\hline FN1893 & 1361 & NO & 2368 & $1-41$ \\
\hline FN1905 & 1487 & NO & 1500 & $1-20$ \\
\hline FN1950 & 930 & NO & 1025 & $1-37$ \\
\hline FN2047 & 1630 & NO & 2429 & $1-42$ \\
\hline FN2058 & 1794 & NO & 2381 & $1-42$ \\
\hline
\end{tabular}

FIG S1 Comparison of T5aSS autotransporter gene annotations in the F. nucleatum 25586 genome (GCA_000007325.1) from the KEGG database and our reannotaton using Prodigal. Incorrect gene annotations were not due to an improperly assembled genome, but because of software limitations. 
bioRxiv preprint doi: https://doi.org/10.1101/534297; this version posted January 29, 2019. The copyright holder for this preprint (which was not certified by peer review) is the author/funder, who has granted bioRxiv a license to display the preprint in perpetuity. It is made available under aCC-BY-NC-ND 4.0 International license.
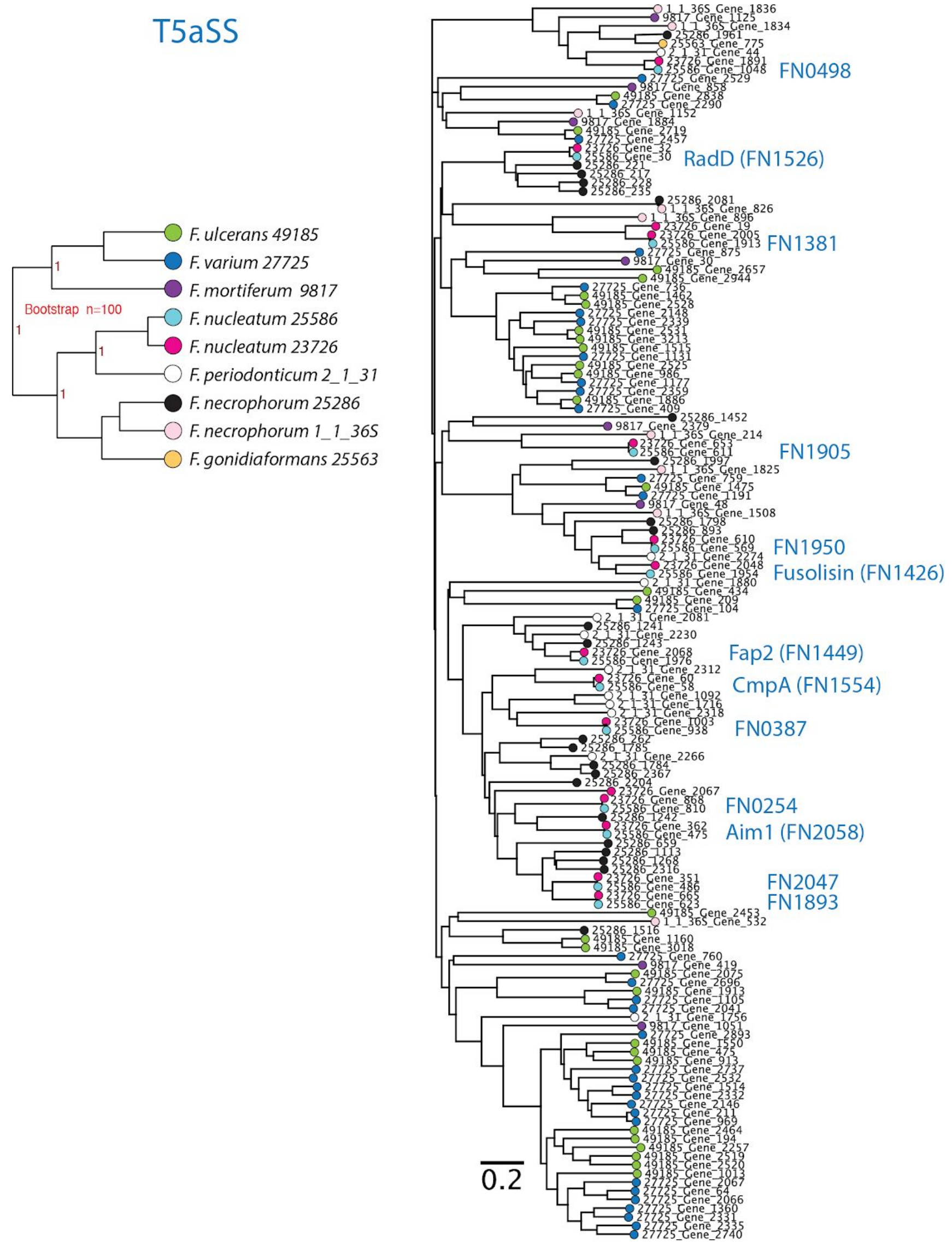

Fig S2 Phylogenetic tree of whole T5aSS autotransporters. Nodes on the tree are colored based on the strain of Fusobacterium, and gene names correspond to those found in Table S2 and the FusoPortal database. 


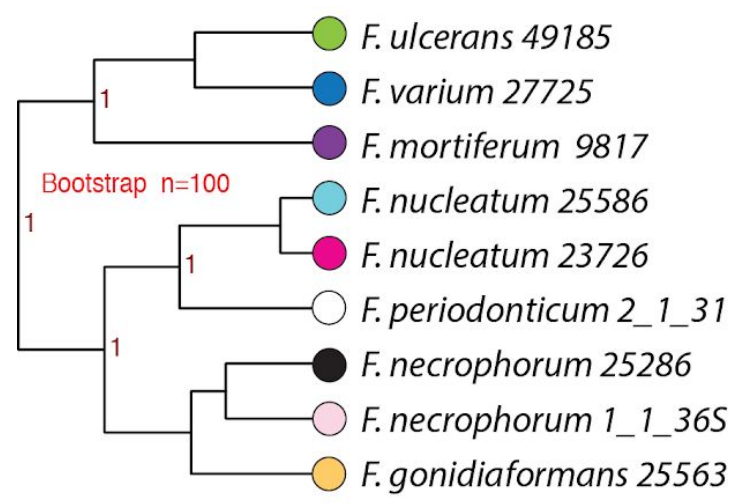

T5bSS

\section{TpsA}

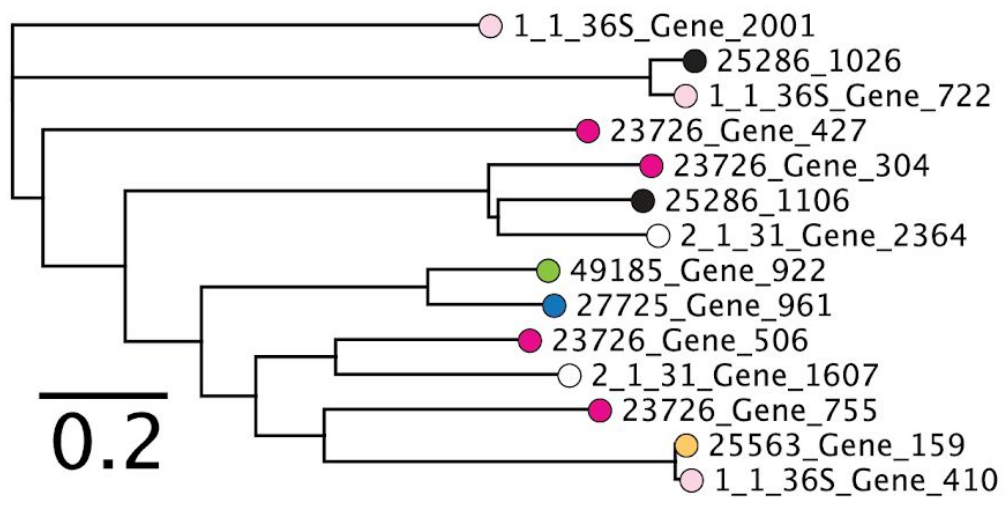

TpsB

23726_Gene_414

25286_1025

1 1 36 S Gene 723

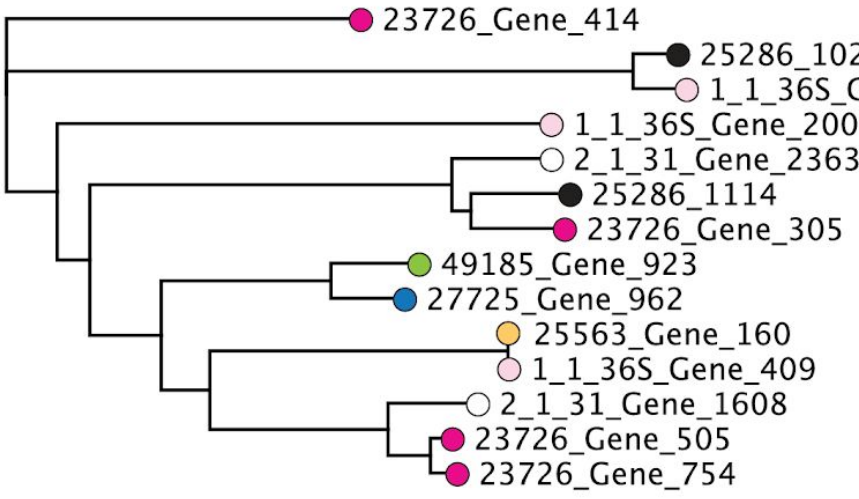

Fig S3 Phylogenetic tree of whole T5bSS two-partner secretion autotransporters. TpsA corresponds to the large, secreted effectors proteins, and TpsB represents the outer membrane embedded $\beta$-barrel translocation proteins. Nodes on the tree are colored based on the strain of Fusobacterium, and gene names correspond to those found in Table S2 and the FusoPortal database. 
bioRxiv preprint doi: https://doi.org/10.1101/534297; this version posted January 29, 2019. The copyright holder for this preprint (which was not certified by peer review) is the author/funder, who has granted bioRxiv a license to display the preprint in perpetuity. It is made available under aCC-BY-NC-ND 4.0 International license.

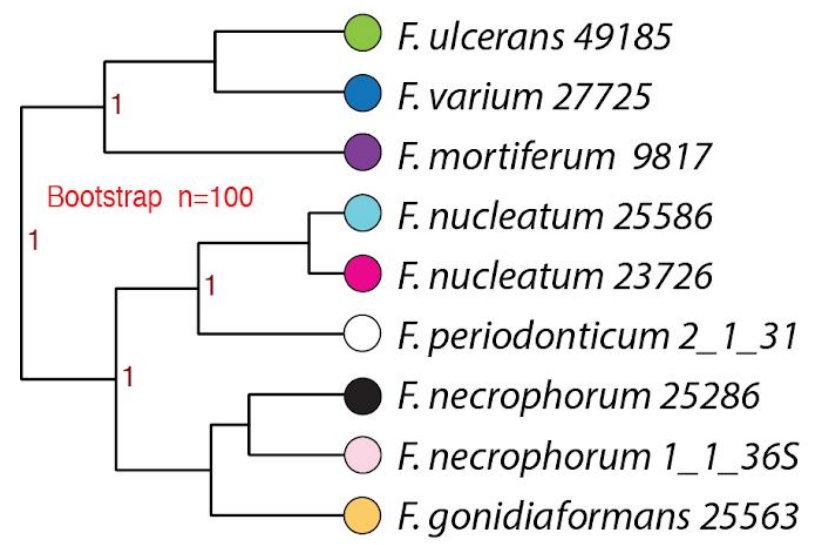

\section{T5cSS}

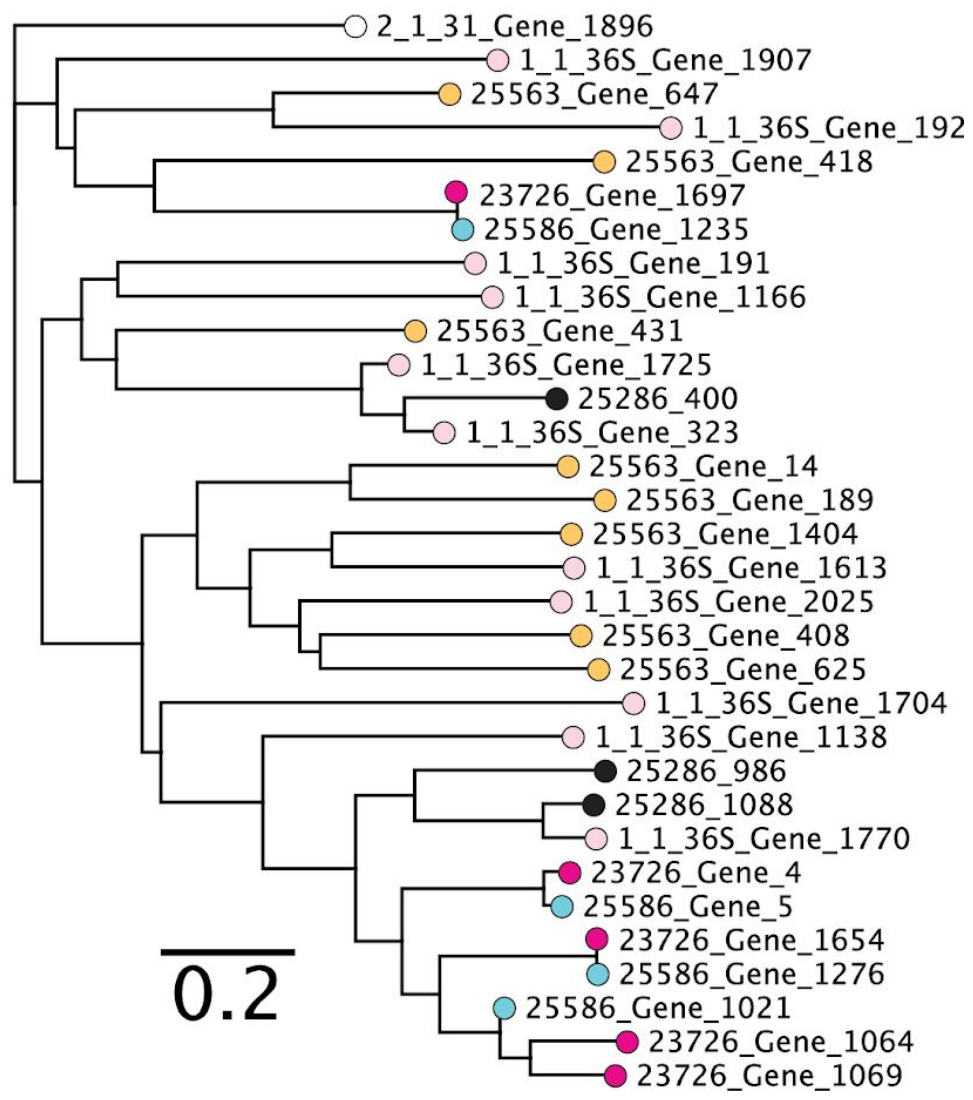

Fig S4 Phylogenetic tree of whole T5cSS trimeric autotransporters. Nodes on the tree are colored based on the strain of Fusobacterium, and gene names correspond to those found in Table S2 and the FusoPortal database.

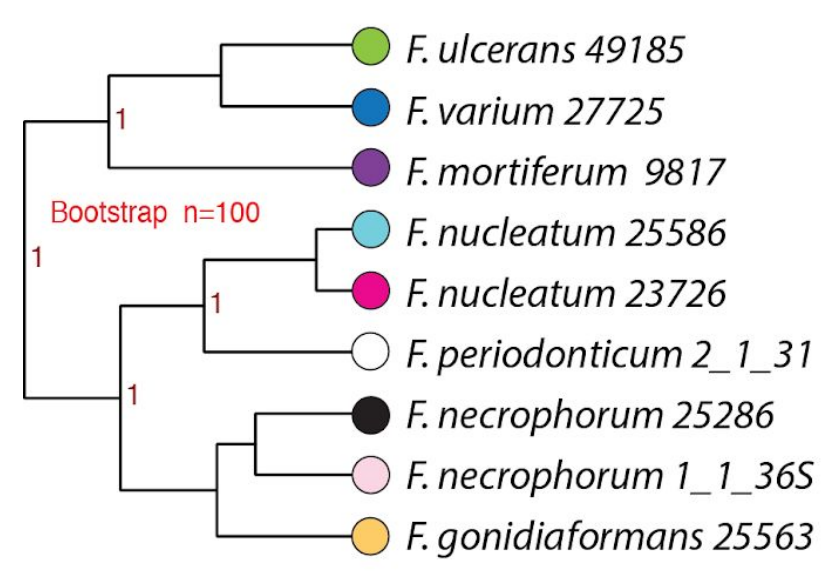

\section{T5dSS}

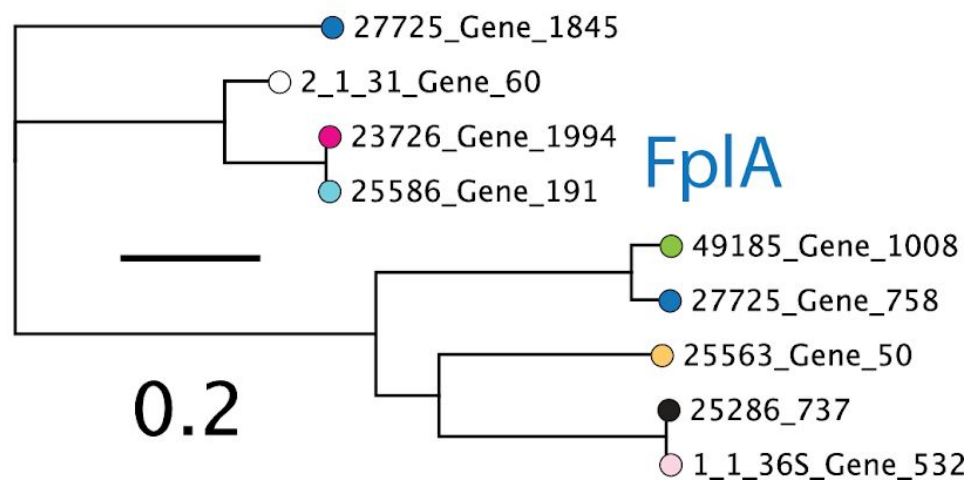

Fig S5 Phylogenetic tree of whole T5dSS phospholipase autotransporters. Nodes on the tree are colored based on the strain of Fusobacterium, and gene names correspond to those found in Table S2 and the FusoPortal database. 
bioRxiv preprint doi: https://doi.org/10.1101/534297; this version posted January 29, 2019. The copyright holder for this preprint (which was not certified by peer review) is the author/funder, who has granted bioRxiv a license to display the preprint in perpetuity. It is made available under aCC-BY-NC-ND 4.0 International license.
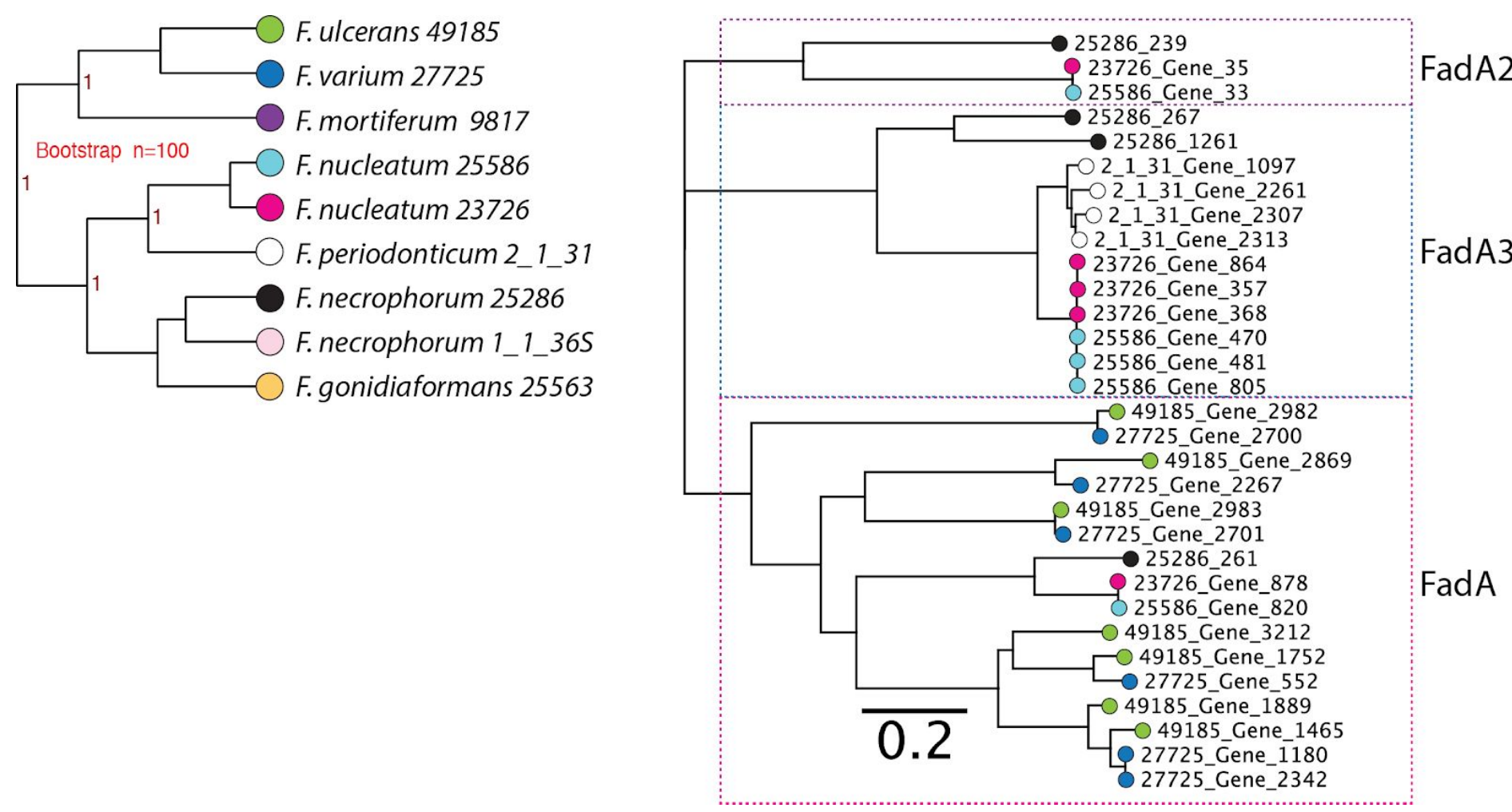

Fig S6 Phylogenetic tree of whole FadA family proteins. Nodes on the tree are colored based on the strain of Fusobacterium, and gene names correspond to those found in Table S2 and the FusoPortal database. 
bioRxiv preprint doi: https://doi.org/10.1101/534297; this version posted January 29, 2019. The copyright holder for this preprint (which was not certified by peer review) is the author/funder, who has granted bioRxiv a license to display the preprint in perpetuity. It is made available under aCC-BY-NC-ND 4.0 International license.

\begin{tabular}{|c|c|}
\hline $\begin{array}{l}\text { Consensus } \\
\text { Identity }\end{array}$ & 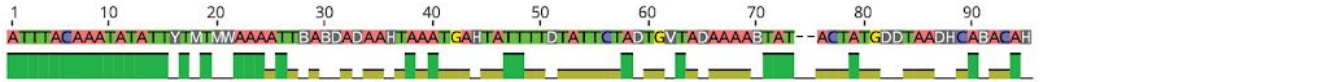 \\
\hline $\begin{array}{l}\text { 1. fadA3a } \\
\text { 2. fadA3c } \\
\text { 3. fadA3b }\end{array}$ & 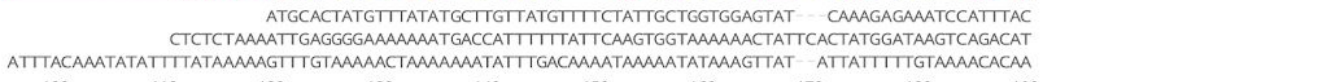 \\
\hline $\begin{array}{l}\text { Consensus } \\
\text { Identity }\end{array}$ & 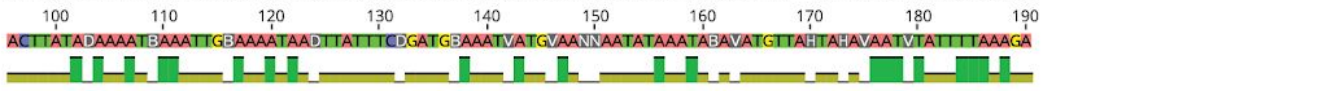 \\
\hline $\begin{array}{l}\text { 1. fadA3a } \\
\text { 2. fadA3c } \\
\text { 3. fadA3b }\end{array}$ & 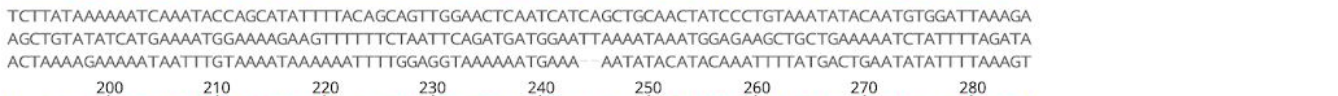 \\
\hline $\begin{array}{l}\text { Consensus } \\
\text { Identity }\end{array}$ & 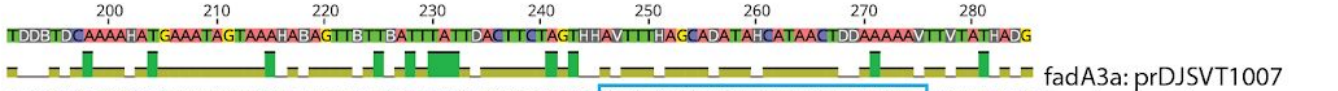 \\
\hline $\begin{array}{l}\text { 1. fadABa } \\
\text { 2. fadA3c } \\
\text { 3. fadABb }\end{array}$ & 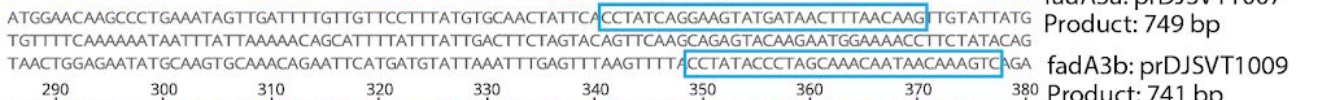 \\
\hline $\begin{array}{l}\text { Consensus } \\
\text { Identity }\end{array}$ & VIDAVDAGTAAHAAHAGVTGGDATGBATTATDATATIGGAAADATDCTDHIBDDCCCTATVIHTATBHTDAAATGVİAHAGTAANANAGTAADVIDC \\
\hline $\begin{array}{l}\text { 1. fadA3a } \\
\text { 2. fadA3c } \\
\text { 3. fadA3b }\end{array}$ & $\begin{array}{l}\text { GGAGTITTATTATTAAATGGTATGCCTCATTCTCTTGGAATGATGTTTCCATTCCTATGTATGTTAGGAATAGCTATGGTTGCAGCACCAGGTGC } \\
\text { CTACAGGGACAACAGCTGTGATGATTATGAAAGTGGAAAAATACTGTTAGAGCTATCTCCAAGTITAGATGGAACAGTAA ATAGTAAAATIT } \\
\text { AATAGAGTAAAAAATGGTAGAACAGAATATAATATGGAAGATIITCTAAGAAGCTTAGAATTATCCTATAATAATAAACCAATA AGTAATCCAC }\end{array}$ \\
\hline $\begin{array}{l}\text { Consensus } \\
\text { Identity }\end{array}$ & 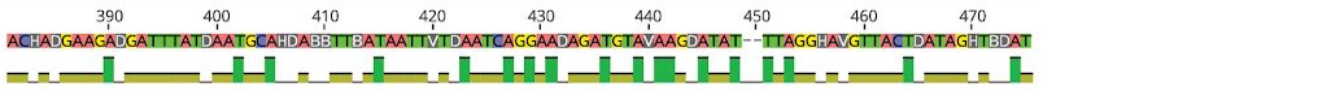 \\
\hline $\begin{array}{l}\text { 1. fadA3a } \\
\text { 2. fadA3c } \\
\text { 3. fadA3b }\end{array}$ & 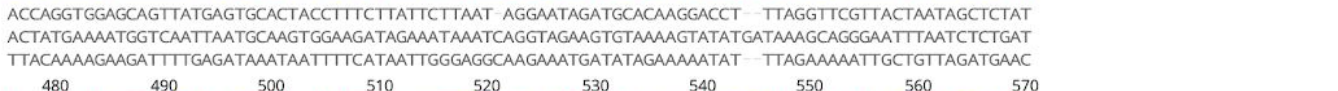 \\
\hline $\begin{array}{l}\text { Consensus } \\
\text { Identity }\end{array}$ & 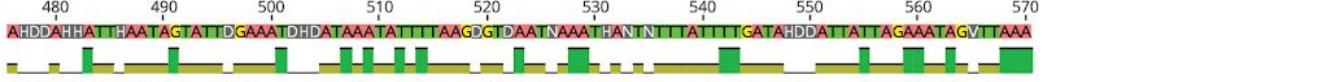 \\
\hline $\begin{array}{l}\text { 1. fadA3a } \\
\text { 2. fadA3c } \\
\text { 3. fadA3b }\end{array}$ & 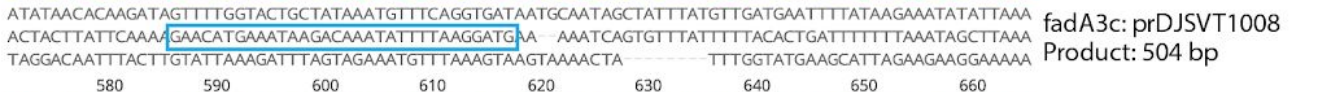 \\
\hline $\begin{array}{l}\text { Consensus } \\
\text { Identity }\end{array}$ & 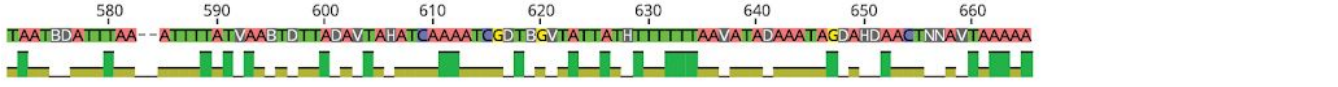 \\
\hline $\begin{array}{l}\text { 1. fadA3a } \\
\text { 2. fadA3c } \\
\text { 3. fadA3b }\end{array}$ & 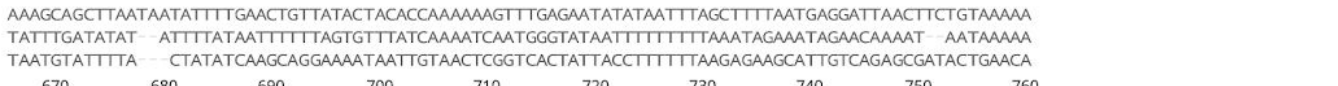 \\
\hline $\begin{array}{l}\text { Consensus } \\
\text { Identity }\end{array}$ & 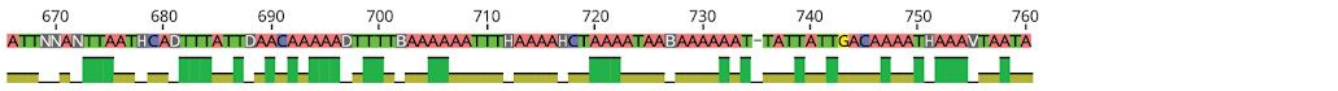 \\
\hline $\begin{array}{l}\text { 1. fadA3a } \\
\text { 2. fadA3c } \\
\text { 3. fadA3b }\end{array}$ & 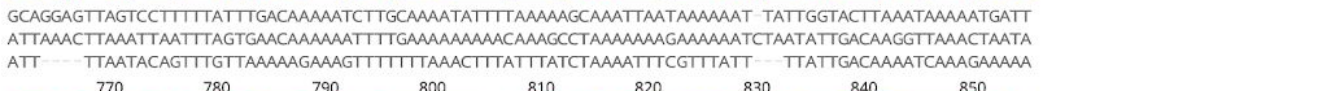 \\
\hline $\begin{array}{l}\text { Consensus } \\
\text { Identity }\end{array}$ & 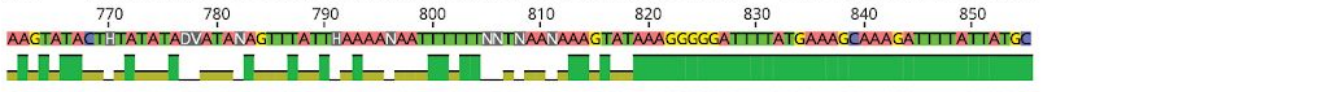 \\
\hline $\begin{array}{l}\text { 1. fadA3a } \\
\text { 2. fadA3c } \\
\text { 3. fadA3b }\end{array}$ & 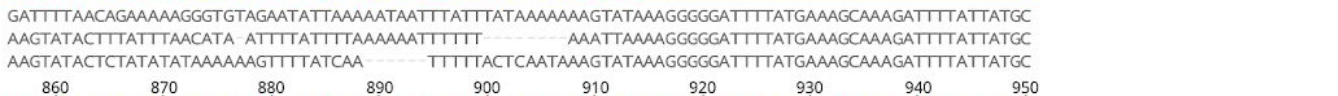 \\
\hline $\begin{array}{l}\text { Consensus } \\
\text { Identity }\end{array}$ & 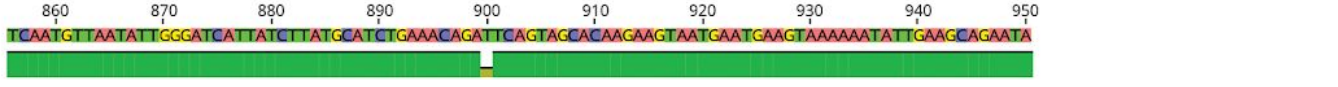 \\
\hline $\begin{array}{l}\text { 1. fadA3a } \\
\text { 2. fadA3c } \\
\text { 3. fadA3b }\end{array}$ & $\begin{array}{l}\text { TCAATGTTAATATTGGGATCATTATCTTATGCATCTGAAACAGATTCAGTAGCACAAGAAGTAATGAATGAAGTAAAAAATTATTGAAGCAGAATA } \\
\text { TCAATTTAATATTGGGATCATTATCTTATGCATCTGAAACAGACTCAGTAGCACAAGAAGTAATGAATGAAGTAAAAAATATTGAGCAGAATA } \\
\text { TCAATGTTAATATTGGGATCATTATCITATGCATCTGAAACAGATTCAGTAGCACAAGAAGTAATGAATGAAGTAAAAAATATTGAAGCAGAATA }\end{array}$ \\
\hline $\begin{array}{l}\text { Consensus } \\
\text { Identity }\end{array}$ & 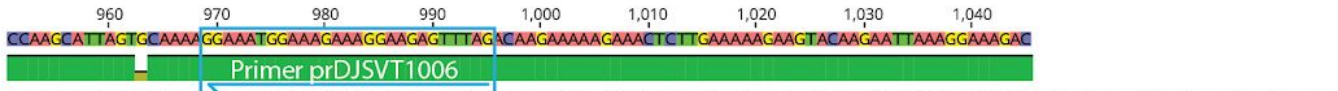 \\
\hline $\begin{array}{l}\text { 1. fadA3a } \\
\text { 2. fadA3c } \\
\text { 3. fadA3b }\end{array}$ & 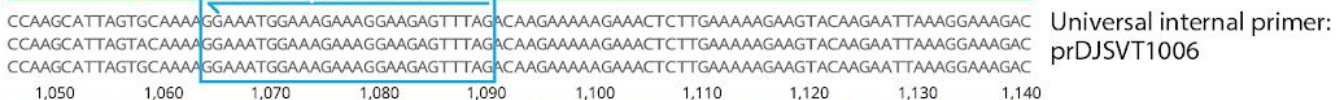 \\
\hline $\begin{array}{l}\text { Consensus } \\
\text { Identity }\end{array}$ & AACTAGGAAGAGAAGAACTITATGCTAAATTAAAAGAAGACTCAAAAATAAGATGGCATAGAGACAAGTACAAGAAACTACTAAAAAGATITGAC \\
\hline $\begin{array}{l}\text { 1. fadA3a } \\
\text { 2. fadA3c } \\
\text { 3. fadA3b }\end{array}$ & 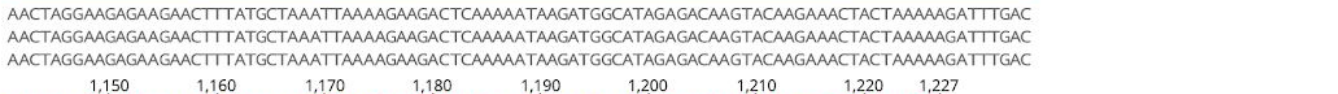 \\
\hline $\begin{array}{l}\text { Consensus } \\
\text { Identity }\end{array}$ & 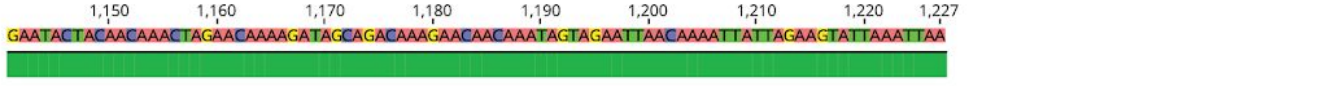 \\
\hline $\begin{array}{l}\text { 1. fadA3a } \\
\text { 2. fadA3c } \\
\text { 3. fadA3b }\end{array}$ & $\begin{array}{l}\text { GAATACTACAACAAACTAGAACAAAAGATAGCAGACAAAGAACAACAAATAGTAGAATTAACAAAATTATTAGAAGTATTAAATTAA } \\
\text { GAATACTACAACAAACTAGAACAAAAGATAGCAGACAAAGAACAACAAATAGTAGAATTAACAAAATTATTAGAAGTATTAAATTAA } \\
\text { GAATACTACAACAAACTAGAACAAAAGATAGCAGACAAAGAACAACAAATAGTAGAATTAACAAAATTATTAGAAGTTTAAATTAA }\end{array}$ \\
\hline
\end{tabular}

Fig S7 Upstream and coding regions of fadA3 genes in F. nucleatum 23726. A universal reverse primer for gene validation PCR (prDJSVT1006) is paired with a forward primer to produce the indicated bp product to validate these genes are indeed three separate copies in the genome (Fig. 8D). 
bioRxiv preprint doi: https://doi.org/10.1101/534297; this version posted January 29, 2019. The copyright holder for this preprint (which was not certified by peer review) is the author/funder, who has granted bioRxiv a license to display the preprint in perpetuity. It is made available under aCC-BY-NC-ND 4.0 International license.

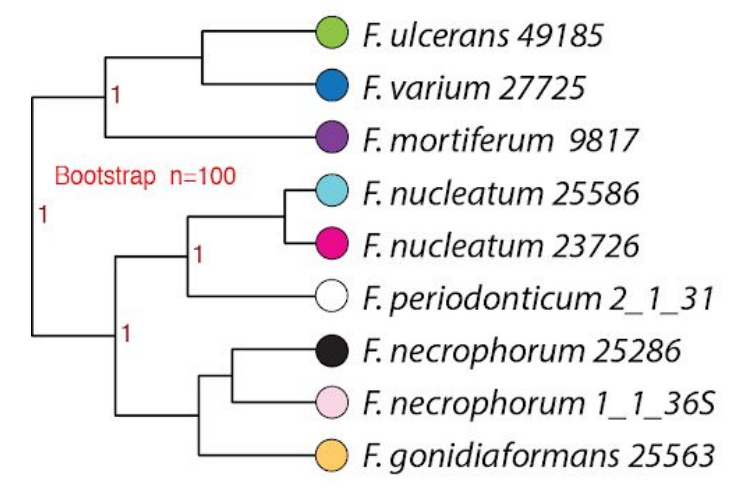

\section{MORN2 \\ Domain \\ Proteins}

F. gonidiaformans 25563

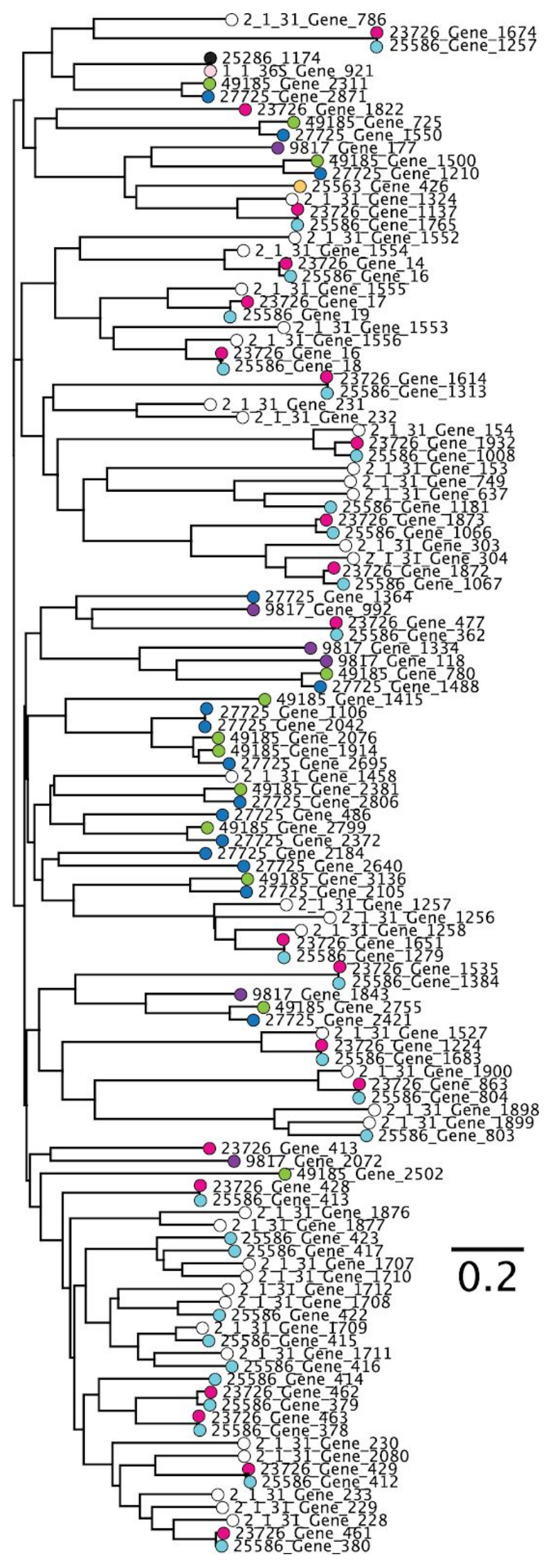

Fig S8 Phylogenetic tree of whole MORN2 domain family proteins. Nodes on the tree are colored based on the strain of Fusobacterium, and gene names correspond to those found in Table S2 and the FusoPortal database. 


\section{REFERENCES}

1. Casadevall A, Pirofski LA. 1999. Host-pathogen interactions: redefining the basic concepts of virulence and pathogenicity. Infect Immun 67:3703-3713.

2. Casadevall A, Pirofski LA. 2000. Host-pathogen interactions: basic concepts of microbial commensalism, colonization, infection, and disease. Infect Immun 68:6511-6518.

3. Didelot X, Walker AS, Peto TE, Crook DW, Wilson DJ. 2016. Within-host evolution of bacterial pathogens. Nat Rev Microbiol 14:150-162.

4. Ham H, Sreelatha A, Orth K. 2011. Manipulation of host membranes by bacterial effectors. Nat Rev Microbiol 9:635-646.

5. Costa TRD, Felisberto-Rodrigues C, Meir A, Prevost MS, Redzej A, Trokter M, Waksman G. 2015. Secretion systems in Gram-negative bacteria: structural and mechanistic insights. Nat Rev Microbiol 13:343-359.

6. Desvaux M, Khan A, Beatson SA, Scott-Tucker A, Henderson IR. 2005. Protein secretion systems in Fusobacterium nucleatum: genomic identification of Type 4 piliation and complete Type $\mathrm{V}$ pathways brings new insight into mechanisms of pathogenesis. Biochim Biophys Acta 1713:92-112.

7. Kaplan CW, Ma X, Paranjpe A, Jewett A, Lux R, Kinder-Haake S, Shi W. Fusobacterium nucleatum Outer Membrane Proteins Fap2 and RadD Induce Cell Death in Human Lymphocytes.

8. Casasanta MA, Yoo CC, Smith HB, Duncan AJ, Cochrane K, Varano AC, Allen-Vercoe E, Slade DJ. 2017. A chemical and biological toolbox for Type Vd secretion: Characterization of the phospholipase A1 autotransporter FplA from Fusobacterium nucleatum. J Biol Chem 292:20240-20254.

9. Guérin J, Bigot S, Schneider R, Buchanan SK, Jacob-Dubuisson F. 2017. Two-Partner Secretion: Combining Efficiency and Simplicity in the Secretion of Large Proteins for Bacteria-Host and Bacteria-Bacteria Interactions. Front Cell Infect Microbiol 7:148. 
10. Leo JC, Grin I, Linke D. 2012. Type V secretion: mechanism(s) of autotransport through the bacterial outer membrane. Philos Trans R Soc Lond B Biol Sci 367:1088-1101.

11. Higgins LM, Frankel G, Connerton I, Gonçalves NS, Dougan G, MacDonald TT. 1999. Role of bacterial intimin in colonic hyperplasia and inflammation. Science 285:588-591.

12. Leo JC, Oberhettinger $P$, Schütz M, Linke D. 2015. The inverse autotransporter family: intimin, invasin and related proteins. Int J Med Microbiol 305:276-282.

13. El Tahir Y, Skurnik M. 2001. YadA, the multifaceted Yersinia adhesin. Int J Med Microbiol 291:209-218.

14. Abby SS, Cury J, Guglielmini J, Néron B, Touchon M, Rocha EPC. 2016. Identification of protein secretion systems in bacterial genomes. Sci Rep 6:23080.

15. Brennan CA, Garrett WS. 2018. Fusobacterium nucleatum - symbiont, opportunist and oncobacterium. Nat Rev Microbiol.

16. Gagnaire A, Nadel B, Raoult D, Neefjes J, Gorvel J-P. 2017. Collateral damage: insights into bacterial mechanisms that predispose host cells to cancer. Nat Rev Microbiol 15:109-128.

17. Han YW. 2015. Fusobacterium nucleatum: a commensal-turned pathogen. Curr Opin Microbiol 23:141-147.

18. Castellarin M, Warren RL, Freeman JD, Dreolini L, Krzywinski M, Strauss J, Barnes R, Watson P, Allen-Vercoe E, Moore RA, Holt RA. 2012. Fusobacterium nucleatum infection is prevalent in human colorectal carcinoma. Genome Res 22:299-306.

19. Kostic AD, Gevers D, Pedamallu CS, Michaud M, Duke F, Earl AM, Ojesina AI, Jung J, Bass AJ, Tabernero J, Baselga J, Liu C, Shivdasani RA, Ogino S, Birren BW, Huttenhower C, Garrett WS, Meyerson M. 2012. Genomic analysis identifies association of Fusobacterium with colorectal carcinoma. Genome Res 22:292-298.

20. Kostic AD, Chun E, Robertson L, Glickman JN, Gallini CA, Michaud M, Clancy TE, Chung DC, Lochhead 
bioRxiv preprint doi: https://doi.org/10.1101/534297; this version posted January 29, 2019. The copyright holder for this preprint (which was not certified by peer review) is the author/funder, who has granted bioRxiv a license to display the preprint in perpetuity. It is made available under aCC-BY-NC-ND 4.0 International license.

P, Hold GL, El-Omar EM, Brenner D, Fuchs CS, Meyerson M, Garrett WS. 2013. Fusobacterium

nucleatum potentiates intestinal tumorigenesis and modulates the tumor-immune microenvironment. Cell Host Microbe 14:207-215.

21. Yu T, Guo F, Yu Y, Sun T, Ma D, Han J, Qian Y, Kryczek I, Sun D, Nagarsheth N, Chen Y, Chen H, Hong J, Zou W, Fang J-Y. 2017. Fusobacterium nucleatum Promotes Chemoresistance to Colorectal Cancer by Modulating Autophagy. Cell 170:548-563.e16.

22. Bullman S, Pedamallu CS, Sicinska E, Clancy TE, Zhang X, Cai D, Neuberg D, Huang K, Guevara F, Nelson T, Chipashvili O, Hagan T, Walker M, Ramachandran A, Diosdado B, Serna G, Mulet N, Landolfi S, Ramon Y Cajal S, Fasani R, Aguirre AJ, Ng K, Élez E, Ogino S, Tabernero J, Fuchs CS, Hahn WC, Nuciforo P, Meyerson M. 2017. Analysis of Fusobacterium persistence and antibiotic response in colorectal cancer. Science 358:1443-1448.

23. Flanagan L, Schmid J, Ebert M, Soucek P, Kunicka T, Liska V, Bruha J, Neary P, Dezeeuw N, Tommasino M, Jenab M, Prehn JHM, Hughes DJ. 2014. Fusobacterium nucleatum associates with stages of colorectal neoplasia development, colorectal cancer and disease outcome. Eur J Clin Microbiol Infect Dis 33:1381-1390.

24. Manson McGuire A, Cochrane K, Griggs AD, Haas BJ, Abeel T, Zeng Q, Nice JB, MacDonald H, Birren BW, Berger BW, Allen-Vercoe E, Earl AM. 2014. Evolution of invasion in a diverse set of Fusobacterium species. MBio 5:e01864.

25. Gursoy UK, Könönen E, Uitto V-J. 2008. Intracellular replication of fusobacteria requires new actin Ælament formation of epithelial cells. APMIS 116:1063-1070.

26. Karpathy SE, Qin X, Gioia J, Jiang H, Liu Y, Petrosino JF, Yerrapragada S, Fox GE, Haake SK, Weinstock GM, Others. 2007. Genome sequence of Fusobacterium nucleatum subspecies polymorphum—a genetically tractable fusobacterium. PLoS One 2:e659.

27. Wu C, Al Mamun AAM, Luong TT, Hu B, Gu J, Lee JH, D’Amore M, Das A, Ton-That H. 2018. Forward 
Genetic Dissection of Biofilm Development by Fusobacterium nucleatum: Novel Functions of Cell Division Proteins FtsX and EnvC. MBio 9.

28. Han YW, Ikegami A, Rajanna C, Kawsar HI, Zhou Y, Li M, Sojar HT, Genco RJ, Kuramitsu HK, Deng CX. 2005. Identification and characterization of a novel adhesin unique to oral fusobacteria. J Bacteriol 187:5330-5340.

29. Sanders BE, Umana A, Lemkul JA, Slade DJ. 2018. FusoPortal: an Interactive Repository of Hybrid MinION-Sequenced Fusobacterium Genomes Improves Gene Identification and Characterization. mSphere 3:e00228-18.

30. Michelle Todd S, Settlage RE, Lahmers KK, Slade DJ. 2018. Fusobacterium Genomics Using MinION and Illumina Sequencing Enables Genome Completion and Correction. mSphere 3:e00269-18.

31. Rubinstein MR, Wang X, Liu W, Hao Y, Cai G, Han YW. 2013. Fusobacterium nucleatum promotes colorectal carcinogenesis by modulating E-cadherin/ $\beta$-catenin signaling via its FadA adhesin. Cell Host Microbe 14:195-206.

32. Oelke AM, Nagaraja TG, Wilkerson MJ, Stewart GC. 2005. The leukotoxin operon of Fusobacterium necrophorum is not present in other species of Fusobacterium. Anaerobe 11:123-129.

33. Zhou H, Bennett G, Hickford JGH. 2009. Variation in Fusobacterium necrophorum strains present on the hooves of footrot infected sheep, goats and cattle. Vet Microbiol 135:363-367.

34. Umana A Slade D. Complete genome sequence of Fusobacterium necrophorum subsp. necrophorum ATCC 25286. Microbiology Resource Announcements.

35. Gill J, Haydon TG, Rawdon TG, McFadden AMJ, Ha H-J, Shen Z, Feng Y, Pang J, Swennes AG, Paster BJ, Dewhirst FE, Fox JG, Spence RP. 2016. Helicobacter bilis and Helicobacter trogontum: infectious causes of abortion in sheep. J Vet Diagn Invest 28:225-234.

36. Henderson A, Ramer-Tait A, Dorn A, Hostetter J, Jergens A, Wannemuehler M. 2008. Helicobacter bilis 
colonization enhances susceptibility to DSS-induced colitis: O-0024. Inflamm Bowel Dis 14:S8.

37. Kapatral V, Anderson I, Ivanova N, Reznik G, Los T, Lykidis A, Bhattacharyya A, Bartman A, Gardner W, Grechkin G, Zhu L, Vasieva O, Chu L, Kogan Y, Chaga O, Goltsman E, Bernal A, Larsen N, D’Souza M, Walunas T, Pusch G, Haselkorn R, Fonstein M, Kyrpides N, Overbeek R. 2002. Genome sequence and analysis of the oral bacterium Fusobacterium nucleatum strain ATCC 25586. J Bacteriol 184:2005-2018.

38. Seemann T. 2014. Prokka: rapid prokaryotic genome annotation. Bioinformatics 30:2068-2069.

39. Hyatt D, Chen G-L, Locascio PF, Land ML, Larimer FW, Hauser LJ. 2010. Prodigal: prokaryotic gene recognition and translation initiation site identification. BMC Bioinformatics 11:119.

40. Henderson IR, Navarro-Garcia F, Desvaux M, Fernandez RC, Ala'Aldeen D. 2004. Type V protein secretion pathway: the autotransporter story. Microbiol Mol Biol Rev 68:692-744.

41. Ohkusa T, Okayasu I, Ogihara T, Morita K, Ogawa M, Sato N. 2003. Induction of experimental ulcerative colitis by Fusobacterium varium isolated from colonic mucosa of patients with ulcerative colitis. Gut 52:79-83.

42. Pallen MJ, Chaudhuri RR, Henderson IR. 2003. Genomic analysis of secretion systems. Curr Opin Microbiol 6:519-527.

43. Coppenhagen-Glazer S, Sol A, Abed J, Naor R, Zhang X, Han YW, Bachrach G. 2015. Fap2 of Fusobacterium nucleatum is a galactose-inhibitable adhesin involved in coaggregation, cell adhesion, and preterm birth. Infect Immun 83:1104-1113.

44. Abed J, Emgård JEM, Zamir G, Faroja M, Almogy G, Grenov A, Sol A, Naor R, Pikarsky E, Atlan KA, Mellul A, Chaushu S, Manson AL, Earl AM, Ou N, Brennan CA, Garrett WS, Bachrach G. 2016. Fap2 Mediates Fusobacterium nucleatum Colorectal Adenocarcinoma Enrichment by Binding to Tumor-Expressed Gal-GalNAc. Cell Host Microbe 20:215-225.

45. Kaplan CW, Lux R, Haake SK, Shi W. 2009. The Fusobacterium nucleatum outer membrane protein RadD 
is an arginine-inhibitable adhesin required for inter-species adherence and the structured architecture of multispecies biofilm. Mol Microbiol 71:35-47.

46. Ruhe ZC, Low DA, Hayes CS. 2013. Bacterial contact-dependent growth inhibition. Trends Microbiol 21:230-237.

47. Hayes CS, Koskiniemi S, Ruhe ZC, Poole SJ, Low DA. 2014. Mechanisms and biological roles of contact-dependent growth inhibition systems. Cold Spring Harb Perspect Med 4.

48. Inatsuka CS, Julio SM, Cotter PA. 2005. Bordetella filamentous hemagglutinin plays a critical role in immunomodulation, suggesting a mechanism for host specificity. Proc Natl Acad Sci U S A 102:18578-18583.

49. Di Venanzio G, Stepanenko TM, García Véscovi E. 2014. Serratia marcescens ShIA pore-forming toxin is responsible for early induction of autophagy in host cells and is transcriptionally regulated by RcsB. Infect Immun 82:3542-3554.

50. Eitel J, Dersch P. 2002. The YadA Protein of Yersinia pseudotuberculosis Mediates High-Efficiency Uptake into Human Cells under Environmental Conditions in Which Invasin Is Repressed. Infect Immun 70:4880-4891.

51. St Geme JW 3rd, Cutter D. 2000. The Haemophilus influenzae Hia adhesin is an autotransporter protein that remains uncleaved at the $\mathrm{C}$ terminus and fully cell associated. J Bacteriol 182:6005-6013.

52. Raghunathan D, Wells TJ, Morris FC, Shaw RK, Bobat S, Peters SE, Paterson GK, Jensen KT, Leyton DL, Blair JMA, Browning DF, Pravin J, Flores-Langarica A, Hitchcock JR, Moraes CTP, Piazza RMF, Maskell DJ, Webber MA, May RC, MacLennan CA, Piddock LJ, Cunningham AF, Henderson IR. 2011. SadA, a trimeric autotransporter from Salmonella enterica serovar Typhimurium, can promote biofilm formation and provides limited protection against infection. Infect Immun 79:4342-4352.

53. Bassler J, Hernandez Alvarez B, Hartmann MD, Lupas AN. 2015. A domain dictionary of trimeric 
autotransporter adhesins. Int J Med Microbiol 305:265-275.

54. Schindler MKH, Schütz MS, Mühlenkamp MC, Rooijakkers SHM, Hallström T, Zipfel PF, Autenrieth IB. 2012. Yersinia enterocolitica YadA mediates complement evasion by recruitment and inactivation of C3 products. J Immunol 189:4900-4908.

55. Rubinstein MR E al. Fusobacterium nucleatum promotes colorectal carcinogenesis by modulating E-cadherin/ $\beta$-catenin signaling via its FadA adhesin. - PubMed - NCBI.

56. Han YW, Redline RW, Li M, Yin L, Hill GB, McCormick TS. 2004. Fusobacterium nucleatum induces premature and term stillbirths in pregnant mice: implication of oral bacteria in preterm birth. Infect Immun 72:2272-2279.

57. Vander Haar EL, So J, Gyamfi-Bannerman C, Han YW. 2018. Fusobacterium nucleatum and adverse pregnancy outcomes: Epidemiological and mechanistic evidence. Anaerobe 50:55-59.

58. Zanzoni A, Spinelli L, Braham S, Brun C. 2017. Perturbed human sub-networks by Fusobacterium nucleatum candidate virulence proteins. Microbiome 5:89.

59. Liu J, Hsieh C-L, Gelincik O, Devolder B, Sei S, Zhang S, Lipkin SM, Chang Y-F. 2019. Proteomic characterization of outer membrane vesicles from gut mucosa-derived fusobacterium nucleatum. J Proteomics.

60. Dy RL, Przybilski R, Semeijn K, Salmond GPC, Fineran PC. 2014. A widespread bacteriophage abortive infection system functions through a Type IV toxin-antitoxin mechanism. Nucleic Acids Res 42:4590-4605.

61. Amer A, Galvin S, Healy CM, Moran GP. 2017. The Microbiome of Potentially Malignant Oral Leukoplakia Exhibits Enrichment for Fusobacterium, Leptotrichia, Campylobacter, and Rothia Species. Front Microbiol 8:2391.

62. Ganly I, Yang L, Giese RA, Hao Y, Nossa CW, Morris LGT, Rosenthal M, Migliacci J, Kelly D, Tseng W, Hu J, Li H, Brown S, Pei Z. 2019. Periodontal pathogens are a risk factor of oral cavity squamous cell 
carcinoma, independent of tobacco and alcohol and human papillomavirus. Int $\mathrm{J}$ Cancer.

63. Al-hebshi NN, Nasher AT, Maryoud MY, Homeida HE, Chen T, Idris AM, Johnson NW. 2017. Inflammatory bacteriome featuring Fusobacterium nucleatum and Pseudomonas aeruginosa identified in association with oral squamous cell carcinoma. Sci Rep 7:1834.

64. Holm K, Collin M, Hagelskjær-Kristensen L, Jensen A, Rasmussen M. 2017. Three variants of the leukotoxin gene in human isolates of Fusobacterium necrophorum subspecies funduliforme. Anaerobe 45:129-132.

65. Narayanan S, Stewart GC, Chengappa MM, Willard L, Shuman W, Wilkerson M, Nagaraja TG. 2002. Fusobacterium necrophorum Leukotoxin Induces Activation and Apoptosis of Bovine Leukocytes. Infect Immun 70:4609-4620.

66. Romanos MA, Clare JJ, Beesley KM, Rayment FB, Ballantine SP, Makoff AJ, Dougan G, Fairweather NF, Charles IG. 1991. Recombinant Bordetella pertussis pertactin (P69) from the yeast Pichia pastoris: high-level production and immunological properties. Vaccine 9:901-906.

67. Ha N-Y, Sharma P, Kim G, Kim Y, Min C-K, Choi M-S, Kim I-S, Cho N-H. 2015. Immunization with an autotransporter protein of Orientia tsutsugamushi provides protective immunity against scrub typhus. PLoS Negl Trop Dis 9:e0003585.

68. Fink DL, Green BA, St Geme JW 3rd. 2002. The Haemophilus influenzae Hap autotransporter binds to fibronectin, laminin, and collagen IV. Infect Immun 70:4902-4907.

69. Wells TJ, Tree JJ, Ulett GC, Schembri MA. 2007. Autotransporter proteins: novel targets at the bacterial cell surface. FEMS Microbiol Lett 274:163-172.

70. Bhattacharyya S, Ghosh SK, Shokeen B, Eapan B, Lux R, Kiselar J, Nithianantham S, Young A, Pandiyan P, McCormick TS, Weinberg A. 2016. FAD-I, a Fusobacterium nucleatum Cell Wall-Associated Diacylated Lipoprotein That Mediates Human Beta Defensin 2 Induction through Toll-Like Receptor-1/2 (TLR-1/2) and 
TLR-2/6. Infect Immun 84:1446-1456.

71. Nagayama M, Sato M, Yamaguchi R, Tokuda C, Takeuchi H. 2001. Evaluation of co-aggregation among Streptococcus mitis, Fusobacterium nucleatum and Porphyromonas gingivalis. Lett Appl Microbiol 33:122-125.

72. Goldberg MB, Theriot JA. 1995. Shigella flexneri surface protein IcsA is sufficient to direct actin-based motility. Proc Natl Acad Sci U S A 92:6572-6576.

73. Lu Q, Xu Y, Yao Q, Niu M, Shao F. 2015. A polar-localized iron-binding protein determines the polar targeting of Burkholderia BimA autotransporter and actin tail formation. Cell Microbiol 17:408-424.

74. Gursoy UK, Könönen E, Uitto V-J. 2008. Intracellular replication of fusobacteria requires new actin filament formation of epithelial cells. APMIS 116:1063-1070.

75. Yoshikawa Y, Ogawa M, Hain T, Chakraborty T, Sasakawa C. 2009. Listeria monocytogenes ActA is a key player in evading autophagic recognition. Autophagy 5:1220-1221.

76. Jiwani S, Alvarado S, Ohr RJ, Romero A, Nguyen B, Jewett TJ. 2013. Chlamydia trachomatis Tarp Harbors Distinct G and F Actin Binding Domains That Bundle Actin Filaments. J Bacteriol 195:708-716.

77. Ikegami A, Chung P, Han YW. 2009. Complementation of the fadA mutation in Fusobacterium nucleatum demonstrates that the surface-exposed adhesin promotes cellular invasion and placental colonization. Infect Immun 77:3075-3079.

78. Bendtsen JD, Nielsen H, von Heijne G, Brunak S. 2004. Improved prediction of signal peptides: SignalP 3.0. J Mol Biol 340:783-795.

79. Finn RD, Attwood TK, Babbitt PC, Bateman A, Bork P, Bridge AJ, Chang H-Y, Dosztányi Z, El-Gebali S, Fraser M, Gough J, Haft D, Holliday GL, Huang H, Huang X, Letunic I, Lopez R, Lu S, Marchler-Bauer A, Mi H, Mistry J, Natale DA, Necci M, Nuka G, Orengo CA, Park Y, Pesseat S, Piovesan D, Potter SC, Rawlings ND, Redaschi N, Richardson L, Rivoire C, Sangrador-Vegas A, Sigrist C, Sillitoe I, Smithers B, 
bioRxiv preprint doi: https://doi.org/10.1101/534297; this version posted January 29, 2019. The copyright holder for this preprint (which was not certified by peer review) is the author/funder, who has granted bioRxiv a license to display the preprint in perpetuity. It is made available under aCC-BY-NC-ND 4.0 International license.

Squizzato S, Sutton G, Thanki N, Thomas PD, Tosatto SCE, Wu CH, Xenarios I, Yeh L-S, Young S-Y, Mitchell AL. 2017. InterPro in 2017-beyond protein family and domain annotations. Nucleic Acids Res 45:D190-D199.

80. Götz S, García-Gómez JM, Terol J, Williams TD, Nagaraj SH, Nueda MJ, Robles M, Talón M, Dopazo J, Conesa A. 2008. High-throughput functional annotation and data mining with the Blast2GO suite. Nucleic Acids Res 36:3420-3435.

81. Gerlt JA, Bouvier JT, Davidson DB, Imker HJ, Sadkhin B, Slater DR, Whalen KL. 2015. Enzyme Function Initiative-Enzyme Similarity Tool (EFI-EST): A web tool for generating protein sequence similarity networks. Biochim Biophys Acta 1854:1019-1037.

82. Shannon P, Markiel A, Ozier O, Baliga NS, Wang JT, Ramage D, Amin N, Schwikowski B, Ideker T. 2003. Cytoscape: a software environment for integrated models of biomolecular interaction networks. Genome Res 13:2498-2504.

83. Snipen L, Liland KH. 2015. micropan: an R-package for microbial pan-genomics. BMC Bioinformatics 16:79. 